\title{
Identification of the Potential Hits for Hindering Interaction of SARS-CoV-2 Main Protease (M pro ) from the Pool of Antiviral Phytochemicals utilizing Molecular Docking and Molecular Dynamics (MD) Simulations
}

Chirag N. Patel

Gujarat University

Dharmesh G. Jaiswal

Gujarat University

Siddhi P. Jani

Gujarat University

Naman Mangukia

Gujarat University

Robin M. Parmar

Gujarat University

Himanshu A. Pandya ( $\square$ hapandya@gujaratuniversity.ac.in )

Gujarat University

\section{Research Article}

Keywords: SARS-CoV-2, Main protease (Mpro), antiviral phytochemicals, Molecular Dynamics (MD) simulation

Posted Date: February 12th, 2021

DOI: https://doi.org/10.21203/rs.3.rs-191629/v1

License: (c) (i) This work is licensed under a Creative Commons Attribution 4.0 International License.

Read Full License 


\section{Identification of the Potential Hits for Hindering Interaction of SARS-CoV-2 Main Protease $\left(\mathbf{M}^{\text {pro }}\right)$ from the Pool of Antiviral Phytochemicals utilizing Molecular Docking and Molecular Dynamics (MD) Simulations}

Chirag N. Patel ${ }^{1}$, Dharmesh G. Jaiswal ${ }^{1}$, Siddhi P. Jani ${ }^{1}$, Naman Mangukia ${ }^{1,2}$, Robin M. Parmar $^{3}$ and Himanshu A. Pandya ${ }^{1 *}$

${ }^{1}$ Department of Botany, Bioinformatics, and Climate Change Impacts Management, School of Sciences, Gujarat University, Ahmedabad, 380009, India.

${ }^{2}$ Bioinnovations, Mumbai, India.

${ }^{3}$ Department of Zoology, School of Sciences, Gujarat University, Ahmedabad, 380009, India.

\section{ORCID profiles}

Chirag N. Patel (http://orcid.org/0000-0003-0777-7720)

Dharmesh G. Jaiswal (https://orcid.org/0000-0002-5643-7151)

Siddhi P. Jani, (https://orcid.org/0000-0003-0693-419X)

Naman Mangukia, (https://orcid.org/0000-0001-9686-9429)

Robin M. Parmar (https://orcid.org/0000-0001-7176-4196)

Himanshu A. Pandya (https://orcid.org/0000-0003-4536-9541)

\section{Details of correspondence}

Prof. (Dr.) Himanshu A. Pandya

Department of Botany, Bioinformatics, and Climate Change Impacts Management, School of Sciences, Gujarat University, Ahmedabad 380009, Gujarat, India.

Email: hapandya@gujaratuniversity.ac.in

\section{Author Approvals}

All authors have seen and approved the manuscript, and that it hasn't been accepted or published elsewhere

Authors have no competing interests to declare. 


\title{
Identification of the Potential Hits for Hindering Interaction of SARS-CoV-2 Main Protease $\left(\mathrm{M}^{\mathrm{pro}}\right)$ from the Pool of Antiviral Phytochemicals utilizing Molecular Docking and Molecular Dynamics (MD) Simulations
}

\begin{abstract}
The novel SARS-CoV-2 is an etiological factor that triggers Coronavirus disease in 2019 (COVID19) and tends to be an imminent occurrence of a pandemic. Out of all recognized solved complexes linked to SARS-CoV, Main protease $\left(\mathrm{M}^{\text {pro }}\right)$ is considered a desirable antiviral phytochemical that play a crucial role in virus assembly and possibly non-interactive capacity to adhere to any viral host protein. In this research, SARS-CoV-2 $\mathrm{M}^{\text {Pro }}$ was chosen as a focus for the detection of possible inhibitors using a variety of different analytical methods such as molecular docking, ADMET analysis, dynamic simulations and binding free energy measurements. Virtual screening of known natural compounds recognized Withanoside V, Withanoside VI, Racemoside B, Racemoside A and Shatavarin IX as future inhibitors of SARS-CoV-2 $\mathrm{M}^{\text {Pro }}$ with stronger energy binding. Also, simulations of molecular dynamics for a $100 \mathrm{~ns}$ time scale showed that much of the main SARSCoV-2 $\mathrm{M}^{\text {Pro }}$ interactions had been maintained in the simulation routes. Binding free energy calculations using the MM/PBSA method ranked the top five possible natural compounds that can act as effective SARS-CoV-2 $\mathrm{M}^{\text {Pro }}$ inhibitors.
\end{abstract}

Keywords: SARS-CoV-2, Main protease $\left(\mathrm{M}^{\text {pro }}\right)$, antiviral phytochemicals, Molecular Dynamics (MD) simulation 


\section{Identification of the Potential Hits for Hindering Interaction of SARS-CoV-2 Main Protease $\left(M^{p r o}\right)$ from the Pool of Antiviral Phytochemicals utilizing Molecular Docking and Molecular Dynamics (MD) Simulations}

\section{Introduction}

Coronavirus, identified as SARS-CoV-2 and COVID-19 (Coronavirus disease), was declared a pandemic by the WHO (World Health Organization) in March 2020 [1]. Severe Acute Respiratory Syndrome (SARS) was first identified in 2002 while Middle East Respiratory Syndrome (MERS) in 2012 [2][3]. It induces respiratory and gastronomic disease with symptoms such as influenza, fever, and shortness of breath in severe conditions [4]. The first diagnostic case of SARS-CoV-2 was identified on 17 November 2019 in Wuhan, China, as an extreme pneumonia cluster since then, the disease has spread globally with a 50 percent rise in the incidence of infection and a lower diagnosis rate of less than 9.2 percent [5][6]. Till now 1,04,956,439 (dated 6 February 2021, https://www.who.int/data) confirmed cases in 213 COVID-19 countries, no apparent licensed or scientifically validated medication has been produced for COVID-19, and it has become critical to find an appropriate treatment for COVID-19 [7].

Coronavirus belongs to the family Cronaviridaea an enveloped, positively stranded RNA virus [8][9][10]. All the spices of the virus are branched based on genome variations and serological reaction in 7 groups namely 229E (Alpha Coronavirus), NL63 (Alpha Coronavirus), OC43 (Beta Coronavirus), HKU1 (Beta Coronavirus), MERS-CoV (Beta Coronavirus), SARS-CoV (Beta Coronavirus) and SARS-CoV-2 (Beta Coronavirus) [10]. The virus is genetically linked to the previous SARS-CoV 2003 epidemic called SARS-CoV-2 on 11 February this year by the International Committee on Virus Taxonomy (ICTV) [11][12].

Twelve Coronavirus proteins have been identified so far as to be a possible drug target commonly categorised as: structural proteins including Spike protein (S protein), S2 protein, Envelop small membrane protein (E protein), Membrane protein (M protein) and Nucleocapsid protein (N protein) and other non-structural proteins including Main protease ( $\left.\mathbf{M}^{\text {pro }}\right)$, Papain-like protease, Non-structural protein 13 (nsp13, helicase), Non-structural protein 14 (nsp14, N-terminal exoribonuclease and C-terminal guanine-N7 methyltransferase), Non-structural protein 12 (nsp12, RNA-dependent RNA polymerase, RdRp), Non-structural protein 15 (nsp15, Uridylate-specific 
endoribonuclease), Non-structural protein 16 (nsp16, 20-O-methyltransferase) and Non-structural protein 10 [13]. Structural proteins are mainly present on the membrane and Non-structural proteins are responsible for the replication and packaging of the virus nuclear material into the capsid protein coat [14][15]. Blocking any of these proteins can lead to arresting viral growth. There are two main strategies to control CoVs in this pandemic situation, mainly the discovery of (i) inhibitor to prevent the entry of virus in the host cell, and (ii) bioactive compounds that restrict viral replication and transcription. ppla and pplab proteins are required for viral replication and translation, active ppla and pplab are released after proteolytic processing by $\mathbf{M}^{\text {pro }}$ highly conserved protein. The stereotypical role of $\mathrm{M}^{\text {pro }}$ and no similarity with any human protein makes $\mathrm{M}^{\text {pro }}$ an attractive antiviral drug target [16] [17] [18] [19] [20]. 'N-[(5-methylisoxazol-3yl)carbonyl]alanyl-1-valyl-n 1 -((1r,2z)-4-(benzyloxy)-4-oxo-1-([(3r)-2-oxopyrrolidin-3yl]methyl)but-2-enyl)-l-leucinamide' (PubChem Compound CID: 6323191) abbreviated as 'N3' has shown covalent bonding in Computer-Aided Drug Design (CADD) analysis with $\mathrm{M}^{\text {pro }}$. The compound efficiently destroys the virus in in vivo experiments, but clinical findings have not yet been identified which lead to the inclusion of natural alternatives such as phytochemicals as a target against $\mathrm{M}^{\text {pro }}[21]$.

Plants are the source of numerous phytochemicals such as alkaloids, flavonoids, phenols, chalcones, coumarins, lignans, polyketides, alkanes, alkenes, alkynes, basic aromatics, peptides, terpenes and steroids used in antiviral, antifungal and antibacterial medicines [22]. With that focus, this study was done to identify a potential phytochemical inhibitor of $\mathbf{M}^{\text {pro }} .110$ phytochemicals [23][24] were screened based on their binding energy. Further in silico analysis was done through molecular docking, Molecular dynamic, ADMET (Absorption-Distribution-MetabolismExcretion-Toxicity).

\section{Results and discussion}

\section{Virtual screening of SARS-CoV-2 Mpro target}

Virtual screening was conducted to identify the best natural compounds with the ability to inhibit SARS-CoV-2 Mro. Re-docking of the co-crystal ligand, N3 was performed to gauze the exact match into the catalytic site (Cys-His catalytic dyad) of the SARS-CoV-2 M $\mathrm{M}^{\text {pro }}$ and it was confirmed using the RMSD between bound and docked conformations. SARS-CoV-2 Mpro 
contains three domains in which 8 to 101 residues are being found from residues 8 to 101 while antiparallel $\beta$-pleated sheets forms through 102 to 184 residues of domain II.

Domain residues are generated from residues 201 to 303 and have five a-helices grouped into a mostly antiparallel globular cluster, which is linked to Domain II comprises of a long loop structural complexity from residues 185 to 200. Domain I and II contains the binding site of SARSCoV-2 $\mathrm{M}^{\text {pro }}$. The original position and orientation of N3 in I the co-crystallized structure of the structure with PDB ID 6LU7 and (ii) the docking projections were shown in Fig-1. The best dock pose (binding energy $=7.55 \mathrm{kcal} / \mathrm{mol}$ ) with an RMSD of $1.70 \AA$ was chosen with the potency of the docking technique to establish native poses. The cavity described in Fig-1 is the main site to be aimed at $3 \mathrm{CL}^{\text {pro }}$ to inhibit its activity. N3 is a comparatively large molecule in which its backbone generates an antiparallel layer containing residues 164 to 168 (His164, Glu166, Met165,

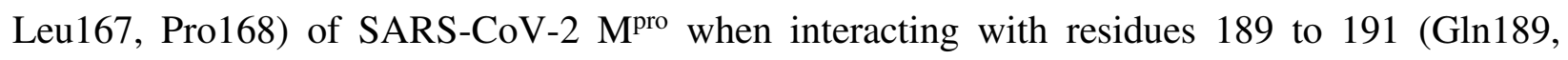
Thr190, Ala191) (Fig-2).

The co-crystallized SARS-CoV-2 $\mathrm{M}^{\text {pro }}$ protein with N3 also indicates a tight covalent bond developed by Cys145 of pro with N3 of $1.8 \AA$ length, which, in turn, makes the interaction with this inhibitor covalently linked to the protein. The re-docked pose had captured $7 \mathrm{H}$-bonds (with Gly143, Phe140, His163, His164, Glu166 and Thr190), 1 amide pi-stacked (Leu141), 5 pi-alkyl (His41, Met49, Leu167, Pro168 and Ala191), 2 carbon-hydrogen bonds (Met165 and His172) and 1 van der Walls (with Asn142) crystal contacts with SARS-CoV-2 M ${ }^{\text {pro }}$. This re-docking confirmation with appropriate dock pose-ability of $\mathrm{N} 3$ and its binding coordinates were encouraged the activity of docking 110 lead-like natural compounds within the binding site of the SARS-CoV-2 $\mathrm{M}^{\text {pro }}$ target. This protein contains the four sites S1', S1, S2, and S4 in its active site region. The inhibitory effect of the SARS-CoV-2 $\mathrm{M}^{\text {pro }}$ targeted protein was prompted by the thiol of a cysteine residue in the $\mathrm{S} 1^{\prime}$ site. The association of Cys 145 with the ligand is therefore essential to inhibit the activity of this protease.

The plant phytochemicals were obtained with higher binding affinity as well as key receptor contacts better than co-crystal ligand (N3). The threshold for interaction affinity was estimated at $8 \mathrm{kcal} / \mathrm{mol}$ to identify Phytochemicals better than the co-crystal $(7.55 \mathrm{kcal} / \mathrm{mol})$ ligand. Among 110 phytochemicals, Top-five compounds have been selected, the binding energy of which varied between 10.04 and $8.3 \mathrm{kcal} / \mathrm{mol}$ (Fig-3) which generated five hydrogen bonds or more with SARS- 
CoV-2 $\mathrm{M}^{\text {pro }}$ at the binding cleft of N3. These were Withanoside V, Withanoside VI, Racemoside B, Racemoside A and Shatavarin IX with the binding energy values 9.84, 9.74, 9.70, 9.68 and 9.35 $\mathrm{kcal} / \mathrm{mol}$, respectively. The most common lead residues (Thr 24, Thr 25, Thr 26, Leu 27, His 41, Thr 45, Ser 46, Glu 47, Met 49, Phe 140, Leu 141, Asn 142, Gly 143, Ser 144, Cys 145, His 163, His 164, Met 165, Glu 166, Leu 167, Pro 168, His 172, Asp 187, Arg 188, Gln 189, Thr 190, Gln 192) formed by Hydrogen Bonds, Hydrophobic contacts, pi-stacks, pi-alkyl and alkyl contacts were found in all the top five compounds (Fig-S1 to Fig-S4). Withanoside V was found as the preeminent inhibitor for SARS-CoV-2 $\mathrm{M}^{\mathrm{pro}}(\mathbf{F i g}-\mathbf{4})$.

\section{In silico ADME/T prediction of top-five compounds}

The drug likelihood of the top-5 compounds was assessed in terms of physicochemically significant descriptors and key pharmacokinetic properties via the Schrodinger QikProp software. N3 was subjected to QikProp ADME/T profiling and a few of the ADME/T parameters are shown in Table-1. Top-5 compounds displayed important values for the properties evaluated and demonstrated drug-like traits based on physico-chemical properties. The ADME/T prediction studies reveal that the top-5 compounds comply with the Lipinski rule of five. They have the sufficient $\log \mathrm{P}$ values for the biological effectiveness and No violation was shown in the desired range of physicochemical and ADME/T parameters. Certain factors significantly, such as bloodbrain permeability and percentage of human oral absorption, are also within the appropriate range as specified for Human usage. Intriguingly, this analysis shows that Withanoside-V possesses the largest polar surface area of the top-5 docked compounds, suggesting the drug similarity of the top-5 docked compounds.

\section{Molecular dynamics simulation}

The best-docked complexes were derived from the molecular docking study to investigate the conformational stability and time-dependent efficiency of ligands in the active pocket of SARS$\mathrm{CoV}-2 \mathrm{M}^{\text {pro }}$. Molecular docking determines the spatial orientation of the ligand in the active site of the receptor. Promptly, other considerations, such as binding affinity and conformational stability, should be considered in the production of compounds targeting SARS-CoV-2 $\mathrm{M}^{\text {pro }}$, in addition to the binding pocket fit. Conformal stability is critical for potent inhibition of SARS$\mathrm{CoV}-2 \mathrm{M}^{\text {pro }}$ and the MD analysis offers a conformational landscape of protein-ligand complexes 
at a given temperature. The MD simulations were conducted for a protein-ligand complex of N3, Withanoside V, Withanoside VI, Racemoside B, Racemoside A and Shatavarin IX using the Schrodinger 2020-4 Desmond module. The trajectory of molecular dynamics has been used to investigate the equilibrium of dynamics over time. An insight into the convergences of simulated protein-ligand complexes can be achieved by taking into account the root mean square deviations (RMSD) of the original structure and the average simulated structure of all MD trajectory frames. Protein-ligand RMSD plots for all top-scoring molecules demonstrated the stability of the docked complexes achieved only after $17 \mathrm{~ns}$ which was similar in the case of the co-crystal compound. Also, RMSD variations were $~ 3 \AA$ for all compounds. Compared to RMSD plots, RMSF protein fluctuations were highest in the residue index window at 30-50, 150-160, 260-280, 190-310 residue regions as some of the amino acid residues found in this window were pocket residues that promote ligand binding (Fig-S5 to Fig-S10). The secondary structural elements contributing to pocket residues were intact in the $\beta$-sheets and loop regions (Fig-S11 to Fig-S16). A thorough examination of fluctuating residues the RMSD plots in this window are enriched with loop components that showed up peaks about $\sim 3 \AA$ in its plots. The ligand RMSD plot revealed the fluctuations for all compounds were ranged between $0.5 \AA$ to $4 \AA$ (Fig-6a). The compactness of the gyration radius calculated showed similar notions for all compounds excluding Withanoside V and Shatavarin IX (Fig-6b). Intramolecular hydrogen bonding was detected in the compounds Withanoside VI, Racemoside A and Shatavarin IX (Fig-6c) which accounted for stronger persisted contacts in their distinct simulation pathways. The molecule surface area (MSA) of Withanoside V was around $650 \AA^{2}$ in most of the frames in the trajectory (Fig. 6d). The solvent-accessible surface area (SASA) and polar surface area (PSA) for Racemoside B and Shatavarin IX were more than $600 \AA^{2}$ in most of the intervals (Fig-6e, f). Both compounds were best in the SARS-CoV-2 $\mathrm{M}^{\text {pro }}$ target, while co-crystal ligand did not establish strong contacts, and its PSA did not lead to strong hydrogen bonding and is always introduced to solvents in most frames.

\section{Preservation of intermolecular contacts in molecular dynamics simulations}

The crystal structure of SARS-CoV-2 M ${ }^{\text {pro }}$ with N3 indicated that its ligand-binding site consists of five adjacent hydrophobic pockets with Met 49, Met 165, Leu 167, Pro 168 and Ala 191. It also developed hydrogen bonds with 11 amino acids viz. Thr 45, Ser 46, Asn 142, Gly 143, Ser 144, Cys 145, His 164, Glu 166, Gln 189, Thr 190 and Gln 192. The water bridges were found with 
inbound ligand with Thr 24 to His 163 and Gln 189 to Gln 192. Fig-7 illustrates the various forms of intermolecular interactions. (Hydrogen bond, hydrophobic and stream bridges) through pocket residue with its bound ligand. The $2 \mathrm{D}$ interaction charts of re-docked and top five natural compounds depicting the retention of contacts along the simulation course as seen in Fig. 8. The co-crystal ligand, N3 preserved almost the entire set of crystal contacts viz. Glu 166 and Gln 189 alkyl moiety, His 164 (water-bridges, 56\%), Gly 143 (Carboxylate group, 35\%). Indeed, all these communications have been captured improving the robustness of the dock posture (Fig. 2) docking process. Withanoside $\mathrm{V}$ was identified as the best scoring compound which developed 1 hydrophobic contact with Cys 145 (42\%), cyclopenta phenathrene pyran ring with polar (Ser 144, $90 \%$, His 163, 80\%, Ser 46, 74\%) and negatively charged amino acids (Glu 47, 84\% and Glu 166, 84\%) (Fig-8). The Withanoside V possessed the same cyclopenta phenanthrene pyran moiety with positively charged (Arg 188, 47\%), negatively charged (Glu 166, 45\%) and 1 polar contact with His $164,65 \%$ which was highest in this analysis (Fig-8c).

Racemoside B in its docking profile developed five hydrogen contacts (Thr 26, Cys 145, His 163, His 164 and Glu 166) and four alkyl interactions with Met 165, Pro 168 and Ala 191 which were correlated using intermolecular interactions profiles. Based on this one unfavorable bond was identified with Thr 24 and maximum interacted part at Thr 24 to Thr 304 (Fig 7d). It also developed alkyl with Met 165, Pro 168 and Ala 191 with one $\pi$-alkyl with Pro 168 amino acids. Racemoside A developed eleven hydrogen bonds (one with Phe 140, Leu 141, Ser 144, Cys 145, His 163, Gln 192, Thr 190 and four with Glu 166) during the docking event. The tetramethyloxapino (oxane) [pentacyclo] icosane generated one alkyl and one pi-alkyl contact with His 41 and Met 49, respectively. One polar and negatively charged contact were developed which retained $37 \%$ of docked interactions (Fig-8e). Shatavarin IX had produced seven hydrogen bonds, one alkyl

and one unfavorable donor-donor interaction during its docking profile which was not reserved in the MD simulation event.

\section{Binding free energy calculations of selected Natural compounds with SARS-CoV-2 Mpro target}

The free energy of binding of top-five Natural compounds and SARS-CoV-2 $\mathrm{M}^{\text {pro }}$ cognate ligand was determined using the MM/PBSA approach. The $100 \mathrm{~ns}$ time scale simulation trajectory was supplied to the YASARA energy macro binding structure. The cognate ligand, N3 secured in - 
$92.43 \mathrm{~kJ} / \mathrm{mol}$ whereas the Withanoside $\mathrm{V}$ obtained the binding for the energy of $-83.45 \mathrm{~kJ} / \mathrm{mol}$ (Fig-9). This observation highlights that N3 developed better crystal contacts along with new contacts resulting in securing the top rank energy among the selected natural compounds. It created new hydrogen bonds with Gln 192 residue which can be beneficial. Withanoside V ranked in second place which developed one hydrophobic interaction with Cys 145 and one hydrogen bond with Gly 143. Withanoside VI ranked the third position with the binding free energy of -61.97 kJ/mol while Racemoside B, Racemoside A and Shatavarin IX possessed -52.44, -56.35 and $53.99 \mathrm{~kJ} / \mathrm{mol}$, respectively.

\section{Materials and Methods}

\section{Data set Preparation}

A library of 110 natural compounds having antiviral properties were retrieved and compiled having demonstrated in vitro anticancer activities from the plants Withania somnifera, Asparagus racemosus, Zinziber officinalis, Allium sativum, Curcuma longa, Adhatoda vasica. All the ligands were prepared for docking by adding charges and hydrogen. These structures were prepared energy minimized and aligned for molecular docking experiment through the Amber03 force field algorithm of YASARA Structure (academic license). Also, crystallographic waters were removed, polar hydrogens and charges to titratable amino acids were also applied which followed by atom typing using Amber03 force field, and geometry optimization using the steepest gradient approach (100 iterations).

SARS-CoV-2 main protease $\left(\mathrm{M}^{\mathrm{Pro}}\right)$ was chosen as the target for the current study. The X-ray diffracted structure was fetched from Protein databank (PDB ID:6LU7; $2.16 \AA$ resolution) which contains the single chain of 306 amino acids and co-crystal ligand N3 (N-[(5-methylisoxazol-3yl)carbonyl]alanyl-1-valyl-n 1 -((1r,2z)-4-(benzyloxy)-4-oxo-1-\{[(3r)-2-oxopyrrolidin-3-

yl]methyl \}but-2-enyl)-l-leucinamide) [25]. YASARA Structure (academic license) was employed for the docking experiment which comprised of water removal, the addition of polar hydrogens, steepest descent method was also used for the energy minimization [12]. 


\section{Virtual library screening upon SARS-CoV-2 Mpro target}

The library of 110 natural compounds was screened against SARS-CoV-2 $\mathrm{M}^{\mathrm{Pro}}$ using AutoDock Vina molecular dock pose search and AMBER03 force field for the scoring algorithm of YASARA software. The re-docking of the N3 co-crystal ligand was performed to validate the scoring mechanism. Whereas, the dock site/grid box size was kept as a $20 \times 20 \times 20 \AA$ with root mean square deviation (RMSD) evaluation. The selected library compounds were sorted because of the highest docking score to pick the top-scoring best compounds for further analysis due to the scoring function of YASARA software [26] which employs high positive as a better affinity of the ligand to the receptor [27]. The binding energy ( $\Delta G_{\text {bind }}$ ) was calculated using the following empirical equation:

$$
\Delta \boldsymbol{G}=\Delta \boldsymbol{G}_{v d W}+\Delta \boldsymbol{G}_{H b o n d}+\Delta \boldsymbol{G}_{\text {elec }}+\Delta \boldsymbol{G}_{\text {tor }}+\Delta \boldsymbol{G}_{\text {desolv }}
$$

where $\Delta G v d W=$ van der Waals term for docking energy; $\Delta G H b o n d=\mathrm{H}$ bonding term for docking energy; $\Delta$ Gelec $=$ electrostatic term for docking energy; $\Delta$ Gtor $=$ torsional free energy term for ligand when the ligand transits from unbounded to bounded state; $\Delta$ Gdesolv $=$ desolvation term for docking energy.

\section{In silico physico-chemical and ADME/T studies}

Physico-chemical and ADME/T properties, that predict both physico-chemical signal descriptors and pharmacokinetically significant molecular properties, have been determined using the Qikprop module of Schrodinger suite 2020-4 [28]. QikProp identifies the comparative ranges of the data features of a molecule with that of recognized medicines. In silico physico-chemical and ADME/T studies of the top 5 docked compounds were predicted to understand its pharmacokinetic nature [29].

Molecular dynamics simulations of the top-scoring molecule with SARS-CoV-2 Mpro target

Physical motions of atoms and molecules of protein-ligand docked complexes have been described by molecular dynamics simulation. Molecular dynamics (MD) simulations were performed in the Desmond (Schrödinger Release 2019-3) kit. The MD simulations of re-docked (N3) and top- 
scored natural compounds were carried out for 100 ns time interval each. Before processing ahead, both receptor-ligand complexes were prepared using the protein preparation wizard of the Schrodinger interface for structural compliance. The insertion of hydrogens, assignment of bonds and filling of missing amino acid side chains and loops with optimization of hydrogen bond assignment, and sampling of water orientation ( $\mathrm{pH}$ 7.0). The periodic simulation box was created using the System Builder module and dissolved through a transferable intermolecular potential with 3 points (TIP3P) water model with the Optimized Potentials for Liquid Simulations (OPLS) all-atom force field with 1000 iterations of the steepest descent technique for system minimization. After equilibrium, an unrestrained production phase took place in the NPT assembly (atoms, pressure and temperature were kept constant) for $100 \mathrm{~ns}$ at $300 \mathrm{~K}$ and 1.01325 bar. Nosé-Hoover thermostat (relaxation time $=1 \mathrm{ps}$ ) and isotropic Martyna-Tobias-Klein barostat (relaxation time $=2$ ps) were used. Short-range interactions (cut-off = $9 \AA$ ) and long-range Columb interaction were assessed using the smooth particle mesh Ewald (PME) method (PME) with a smooth particle network with the RESPA integrator. Confirmed seizures were recovered at the rate of 5 ps. After the simulation was completed, the stability of the system was evaluated by histogram for RMSD, root mean square fluctuations (RMSF), Hydrogen bond analysis, radius of gyration (Rg), torsional Bonds [30][31][32].

\section{Binding free energy calculations of top-scoring molecules with SARS-CoV-2 Mpro target}

The single trajectory method was used to determine Free energy binding using molecular mechanics/Poisson-Boltzmann Surface Area (MM/PBSA) with YASARA Structure. AMBER14 APBS (Adaptive Poisson-Boltzmann Solver) force field was employed to measure the solvent energy and to handle electrostatics [12][33]. The $100 \mathrm{~ns}$ long simulation trajectory of the top five MD natural compounds and the co-crystal ligand was supplied as data.

$$
\begin{gathered}
\Delta G_{\text {bind }}=\Delta G_{\text {complex }(\text { minimized })}-\left[\Delta G_{\text {ligand }(\text { minimized })}+\Delta G_{\text {receptor(minimized })}\right] \\
\text { and } \\
\Delta G_{\text {bind }}=\Delta G_{M M}+\Delta G_{P B}+\Delta G_{S A-T \Delta S}
\end{gathered}
$$

Where $\Delta_{T D S}$ is the conformation entropic contribution, and $\Delta G_{M M}$ is the molecular mechanics' interaction energy (electrostatic + van der Waals interaction) between protein and ligand. $\Delta G_{P B}$ and $\Delta G_{S A}$ depict the polar solvation energy and the nonpolar solvation energy, respectively. 


\section{Conclusion}

The lack of an appropriate medicinal drug or vaccine has already exacerbated the condition of a pandemic epidemic of COVID-19. Since the first step of viral invasion and infection is enabled by significant interactions between human ACE2 and CoV-2 proteins, targeting $\mathrm{M}^{\text {pro }}$ receptors is the crucial technique for developing successful inhibitors driven by computer-aided drug design approaches. This research prioritizes lead compounds against the SARS-CoV-2 M $\mathrm{M}^{\text {pro }}$ complex from a natural compound repository using a hierarchical protocol for simulated sampling, molecular dynamic simulation and free energy binding calculations. Withanoside V, Withanoside VI, Racemoside B, Racemoside A and Shatavarin IX have emerged as a robust natural compound with a stronger binding affinity profile. Molecular dynamic simulations were conducted for all docked complexes at a time scale of $100 \mathrm{~ns}$, showing the structural integrity of protein-ligand complexes. Diverse measurement methods such as RMSD, RMSF, gyration radius, surface area measures have jointly assisted the structural integrity of the complex. Top-ranked compounds retained some of the interactions same as a cognate ligand. Also, the MM/PBSA measurements were used to measure the binding free energy of the top-five natural compounds, demonstrating that greater interaction with the neighboring hydrophobic binding pockets of the ligand-binding help increases the binding free energy while maintaining main receptor contacts. While this report offers valuable perspectives at the preliminary stage of the study, SARS-CoV-2 $\mathrm{M}^{\text {pro }}$ drug design, ligand binding predictions resulting from molecular docking and molecular dynamics simulations can be used to scan and refine natural molecules that need experimental confirmation by in vitro and in vivo studies.

\section{CONFLICTS OF INTEREST}

The authors declare that there are no conflicts of interest.

\section{ACKNOWLEDGMENTS}

This work is supported by the Financial Assistance Programme - Department of Science and Technology [GSBTM/MD/JDR/1409/2017-18] and Gujarat Council on Science and Technology [GUJCOST/Supercomputer/2019-20/1359] had provided grants for the purchase of computer hardware only and is been used up. Author NM gratefully acknowledge SERB, DST, Govt. of India \& CII for Prime Minister Fellowship. The research work is not been granted from any 
fund. The authors gratefully acknowledge the Department of Botany, Bioinformatics and Climate Change Impacts Management, Gujarat University for providing an opportunity to access the bioinformatics research facilities.

\section{Author contributions}

C.N.P., D.G.J and H.A.P. conceptualized and designed the project. C.N.P., R.M.P. and H.A.P. developed methodology. C.N.P. and D.G.J acquired data. C.N.P., S.P.J. and R.M.P. analyzed and interpreted data. C.N.P., D.G.J., S.P.J., N.M., R.M.P. and H.A.P. wrote manuscript. N.M. and R.M.P. provided technical support. R.M.P. and H.A.P. supervised study. The whole manuscript was approved by all authors.

\section{REFERENCES}

[1] T. Acter, N. Uddin, J. Das, A. Akhter, T.R. Choudhury, S. Kim, Evolution of severe acute respiratory syndrome coronavirus 2 (SARS-CoV-2) as coronavirus disease 2019 (COVID19) pandemic: A global health emergency, Sci. Total Environ. 730 (2020) 138996. https://doi.org/10.1016/j.scitotenv.2020.138996.

[2] S. Al Hajjar, Z.A. Memish, K. McIntosh, Middle east respiratory syndrome coronavirus (MERS-CoV): A perpetual challenge, Ann. Saudi Med. 33 (2013) 427-436. https://doi.org/10.5144/0256-4947.2013.427.

[3] Z.A. Memish, S. Perlman, M.D. Van Kerkhove, A. Zumla, Middle East respiratory syndrome, Lancet. 395 (2020) 1063-1077. https://doi.org/10.1016/S0140-6736(19)332210 .

[4] T. Singhal, A Review of Coronavirus Disease-2019 (COVID-19), (2098). https://doi.org/10.1007/s12098-020-03263-6.

[5] H. Nishiura, T. Kobayashi, T. Miyama, A. Suzuki, S.M. Jung, K. Hayashi, R. Kinoshita, Y. Yang, B. Yuan, A.R. Akhmetzhanov, N.M. Linton, Estimation of the asymptomatic ratio of novel coronavirus infections (COVID-19), MedRxiv. (2020). https://doi.org/10.1101/2020.02.03.20020248.

[6] L.F. Moriarty, M.M. Plucinski, B.J. Marston, E. V Kurbatova, B. Knust, E.L. Murray, N. 
Pesik, D. Rose, D. Fitter, M. Kobayashi, M. Toda, P.T. Canty, T. Scheuer, E.S. Halsey, N.J. Cohen, L. Stockman, D.A. Wadford, A.M. Medley, G. Green, J.J. Regan, K.

Tardivel, S. White, C. Brown, C. Morales, C. Yen, B. Wittry, A. Freeland, S. Naramore, R.T. Novak, D. Daigle, M. Weinberg, A. Acosta, C. Herzig, B.K. Kapella, K.R. Jacobson, K. Lamba, ; Atsuyoshi Ishizumi, J. Sarisky, E. Svendsen, T. Blocher, C. Wu, J. Charles, R. Wagner, A. Stewart, P.S. Mead, E. Kurylo, S. Campbell, R. Murray, P. Weidle, M. Cetron, C.R. Friedman, Public Health Responses to COVID-19 Outbreaks on Cruise Ships — Worldwide, February-March 2020, 2019.

https://wwwnc.cdc.gov/travel/notices/warning/novel-coronavirus-china. (accessed January 27, 2021).

[7] Y. Liu, Y. Yang, C. Zhang, F. Huang, F. Wang, J. Yuan, Z. Wang, J. Li, J. Li, C. Feng, Z. Zhang, L. Wang, L. Peng, L. Chen, Y. Qin, D. Zhao, S. Tan, L. Yin, J. Xu, C. Zhou, C. Jiang, L. Liu, Clinical and biochemical indexes from 2019-nCoV infected patients linked to viral loads and lung injury, Sci. China Life Sci. 63 (2020) 364-374. https://doi.org/10.1007/s11427-020-1643-8.

[8] S.M. Poutanen, D.E. Low, Severe acute respiratory syndrome: An update, Curr. Opin. Infect. Dis. 17 (2004) 287-294. https://doi.org/10.1097/01.qco.0000136924.45049.7e.

[9] G. Liya, W. Yuguang, L. Jian, Y. Huaiping, H. Xue, H. Jianwei, M. Jiaju, L. Youran, M. Chen, J. Yiqing, Studies on viral pneumonia related to novel coronavirus SARS-CoV-2, SARS-CoV, and MERS-CoV: a literature review, APMIS. 128 (2020) 423-432. https://doi.org/10.1111/apm.13047.

[10] S. Kumar, R. Nyodu, V.K. Maurya, S.K. Saxena, Morphology, Genome Organization, Replication, and Pathogenesis of Severe Acute Respiratory Syndrome Coronavirus 2 (SARS-CoV-2), in: 2020: pp. 23-31. https://doi.org/10.1007/978-981-15-4814-7_3.

[11] V.K. Bhardwaj, R. Singh, J. Sharma, V. Rajendran, R. Purohit, S. Kumar, Identification of bioactive molecules from tea plant as SARS-CoV-2 main protease inhibitors, J. Biomol. Struct. Dyn. (2020) 1-10. https://doi.org/10.1080/07391102.2020.1766572.

[12] C.N. Patel, S.P. Kumar, H.A. Pandya, R.M. Rawal, Identification of potential inhibitors of 
coronavirus hemagglutinin-esterase using molecular docking, molecular dynamics simulation and binding free energy calculation, Mol. Divers. 1 (2020) 3. https://doi.org/10.1007/s11030-020-10135-w.

[13] L. Guruprasad, Evolutionary relationships and sequence-structure determinants in human SARS coronavirus-2 spike proteins for host receptor recognition, Proteins Struct. Funct. Bioinforma. 88 (2020) 1387-1393. https://doi.org/10.1002/prot.25967.

[14] Endriyas Kelta Wabalo, Abebe Dukessa Dubiwak, Tariku Sime Gizaw, Urge Gerema Kotu, Role of structural and functional proteins of SARS -COV-2, GSC Biol. Pharm. Sci. 12 (2020) 117-129. https://doi.org/10.30574/gscbps.2020.12.3.0275.

[15] W.H. Kong, Y. Li, M.W. Peng, D.G. Kong, X.B. Yang, L. Wang, M.Q. Liu, SARS-CoV2 detection in patients with influenza-like illness, Nat. Microbiol. 5 (2020) 675-678. https://doi.org/10.1038/s41564-020-0713-1.

[16] X. Zhang, H. Cai, J. Hu, J. Lian, J. Gu, S. Zhang, C. Ye, Y. Lu, C. Jin, G. Yu, H. Jia, Y. Zhang, J. Sheng, L. Li, Y. Yang, Epidemiological, clinical characteristics of cases of SARS-CoV-2 infection with abnormal imaging findings, Int. J. Infect. Dis. 94 (2020) 8187. https://doi.org/10.1016/j.ijid.2020.03.040.

[17] Z. Jin, X. Du, Y. Xu, Y. Deng, M. Liu, Y. Zhao, B. Zhang, X. Li, L. Zhang, C. Peng, Y. Duan, J. Yu, L. Wang, K. Yang, F. Liu, R. Jiang, X. Yang, T. You, X. Liu, X. Yang, F. Bai, H. Liu, X. Liu, L. Guddat, W. Xu, G. Xiao, C. Qin, Z. Shi, H. Jiang, Z. Rao, H. Yang, Structure of M pro from COVID-19 virus and discovery of its inhibitors, Nature. (2020). https://doi.org/10.1101/2020.02.26.964882.

[18] L. Wang, B.B. Bao, G.Q. Song, C. Chen, X.M. Zhang, W. Lu, Z. Wang, Y. Cai, S. Li, S. Fu, F.H. Song, H. Yang, J.G. Wang, Discovery of unsymmetrical aromatic disulfides as novel inhibitors of SARS-CoV main protease: Chemical synthesis, biological evaluation, molecular docking and 3D-QSAR study, Eur. J. Med. Chem. 137 (2017) 450-461. https://doi.org/10.1016/j.ejmech.2017.05.045.

[19] J. Cui, F. Li, Z.L. Shi, Origin and evolution of pathogenic coronaviruses, Nat. Rev. Microbiol. 17 (2019) 181-192. https://doi.org/10.1038/s41579-018-0118-9. 
[20] M. Macchiagodena, M. Pagliai, P. Procacci, Identification of potential binders of the main protease 3CLpro of the COVID-19 via structure-based ligand design and molecular modeling, Chem. Phys. Lett. 750 (2020). https://doi.org/10.1016/j.cplett.2020.137489.

[21] X. Zhou, F. Zhong, C. Lin, X. Hu, Y. Zhang, B. Xiong, X. Yin, J. Fu, W. He, J. Duan, Y. Fu, H. Zhou, P.J. McCormick, Q. Wang, J. Li, J. Zhang, Structure of SARS-CoV-2 main protease in the apo state, Springer. (2020). https://doi.org/10.1007/s11427-020-1791-3.

[22] P.G. Mwitari, P.A. Ayeka, J. Ondicho, E.N. Matu, C.C. Bii, Antimicrobial Activity and Probable Mechanisms of Action of Medicinal Plants of Kenya: Withania somnifera, Warbugia ugandensis, Prunus africana and Plectrunthus barbatus, PLoS One. 8 (2013) e65619. https://doi.org/10.1371/journal.pone.0065619.

[23] S. Sabde, H.S. Bodiwala, A. Karmase, P.J. Deshpande, A. Kaur, N. Ahmed, S.K. Chauthe, K.G. Brahmbhatt, R.U. Phadke, D. Mitra, K.K. Bhutani, I.P. Singh, Anti-HIV activity of Indian medicinal plants, J. Nat. Med. 65 (2011) 662-669. https://doi.org/10.1007/s11418011-0513-2.

[24] Z. Lamari, R. Larbi, H. Negache, Trace element content of Zingiber officinalis and Salvia officinalis medicinal plants from Algeria, J. Radioanal. Nucl. Chem. 309 (2016) 17-22. https://doi.org/10.1007/s10967-016-4858-6.

[25] Z. Jin, X. Du, Y. Xu, Y. Deng, M. Liu, Y. Zhao, B. Zhang, X. Li, L. Zhang, C. Peng, Y. Duan, J. Yu, L. Wang, K. Yang, F. Liu, R. Jiang, X. Yang, T. You, X. Liu, X. Yang, F. Bai, H. Liu, X. Liu, L.W. Guddat, W. Xu, G. Xiao, C. Qin, Z. Shi, H. Jiang, Z. Rao, H. Yang, Structure of Mpro from SARS-CoV-2 and discovery of its inhibitors, Nature. 582 (2020) 289-293. https://doi.org/10.1038/s41586-020-2223-y.

[26] S.P. Kumar, C.N. Patel, R.M. Rawal, H.A. Pandya, Energetic contributions of amino acid residues and its cross-talk to delineate ligand-binding mechanism, Proteins Struct. Funct. Bioinforma. 88 (2020) 1207-1225. https://doi.org/10.1002/prot.25894.

[27] C.N. Patel, J.J. Georrge, K.M. Modi, M.B. Narechania, D.P. Patel, F.J. Gonzalez, H.A. Pandya, Pharmacophore-based virtual screening of catechol-o-methyltransferase (COMT) inhibitors to combat Alzheimer's disease, J. Biomol. Struct. Dyn. 36 (2018). 
https://doi.org/10.1080/07391102.2017.1404931.

[28] Schrödinger Release 2020-4: QikProp, Schrödinger,... - Google Scholar, (n.d.). https://scholar.google.co.in/scholar?hl=en\&as_sdt=0\%2C5\&q=Schrödinger+Release+202 $0-$

4\%3A+QikProp\%2C+Schrödinger\%2C+LLC\%2C+New+York\%2C+NY\%2C+2020.\&bt $\mathrm{nG}=($ accessed January 27,2021$)$.

[29] D.K. Sigalapalli, R. Rangaswamy, N.D. Tangellamudi, Novel huperzine A based NMDA antagonists: Insights from molecular docking, ADME/T and molecular dynamics simulation studies, RSC Adv. 10 (2020) 25446-25455. https://doi.org/10.1039/d0ra00722f.

[30] E. Krieger, T. Darden, S.B. Nabuurs, A. Finkelstein, G. Vriend, Making Optimal Use of Empirical Energy Functions: Force-Field Parameterization in Crystal Space, Wiley Online Libr. 57 (2004) 678-683. https://doi.org/10.1002/prot.20251.

[31] E. Krieger, G. Vriend, New ways to boost molecular dynamics simulations, J. Comput. Chem. 36 (2015) 996-1007. https://doi.org/10.1002/jcc.23899.

[32] Y. Kumar, H. Singh, C.N. Patel, In silico prediction of potential inhibitors for the main protease of SARS-CoV-2 using molecular docking and dynamics simulation based drugrepurposing, J. Infect. Public Health. 13 (2020) 1210-1223. https://doi.org/10.1016/j.jiph.2020.06.016.

[33] I. Massova, P.A. Kollman, Combined molecular mechanical and continuum solvent approach (MM- PBSA/GBSA) to predict ligand binding, Perspect. Drug Discov. Des. 18 (2000) 113-135. https://doi.org/10.1023/A:1008763014207. 


\section{List of Figures}

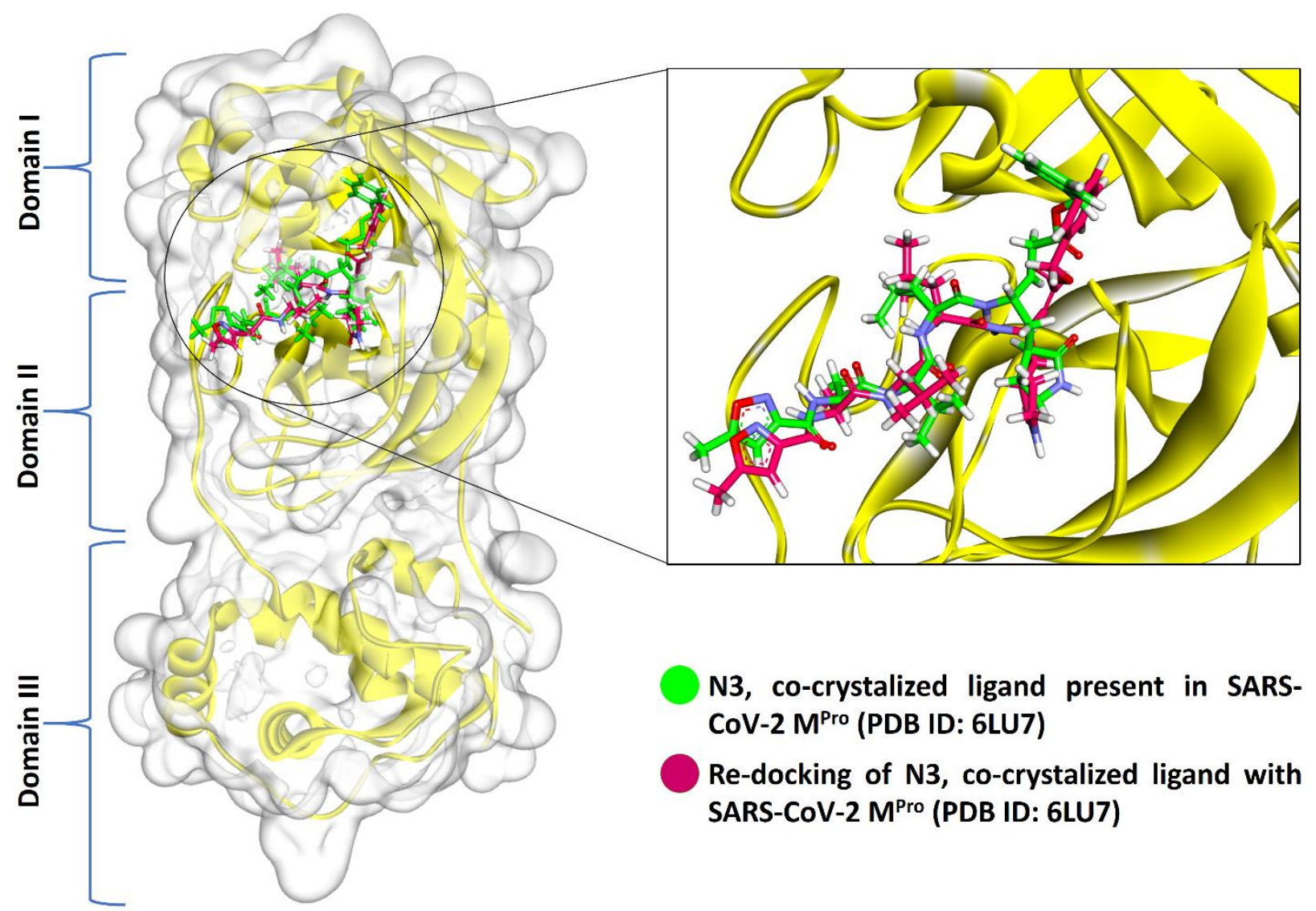

Fig-1 Three-dimensional representation of the co-crystal ligand N3 in the binding cleft of SARSCoV-2 M $\mathrm{M}^{\text {Pro }}$ (PDB ID: 6LU7). Green color represents the pre-docked pose of co-crystal ligand N3 and re-docked pose of co-crystal ligand N3 was preserved in magenta color. 


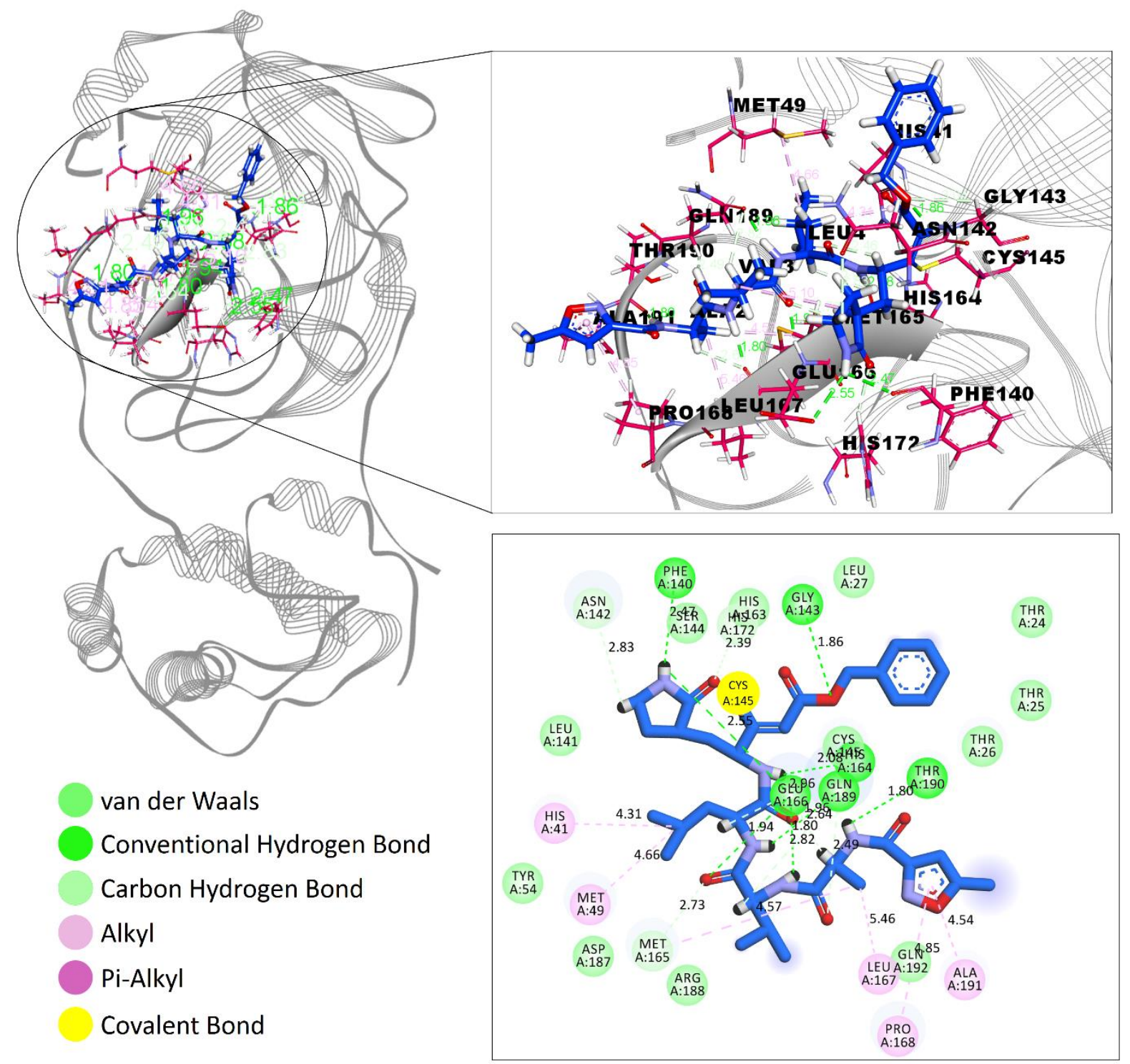

Fig-2 Interaction of N3 in the binding cleft of SARS-CoV-2 M ${ }^{\text {ro }}$ (PDB ID: 6LU7) of COVID-19 shown in (a) $3 \mathrm{D}$ representation and (b) $2 \mathrm{D}$ representation (for better clarity) describing ligands interactions by formation of various $\mathrm{H}$-bonds and hydrophobic interactions with protein at the active site of the protein. 


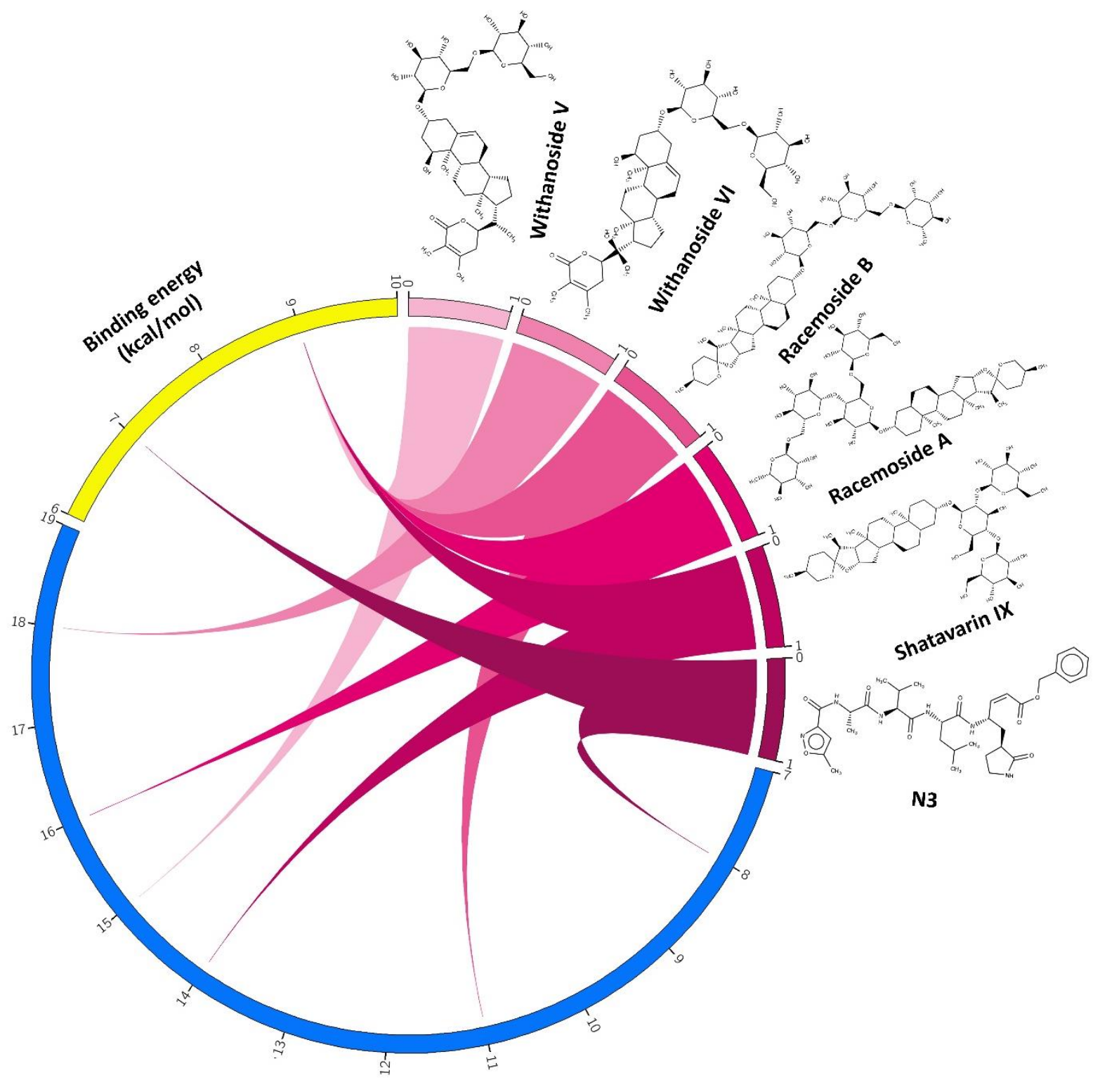

Hydrogen bonds

Fig-3 N3, Withanoside-V, Withanoside-VI, Racemoside-B, Racemoside-A, Shatavarin-IX are depicted along with their Hydrogen bonds and Binding energy information using Circos representation. All the 3 entities- the compounds, Hydrogen bond and Binding energy are shown using 3 separate ideograms. The 6 compounds are drawn from light to dark magenta color shades and their respective values of Hydrogen bond (Blue color) and Binding energy (Yellow color) are displayed using connecting colored ribbons and numbering scales. 


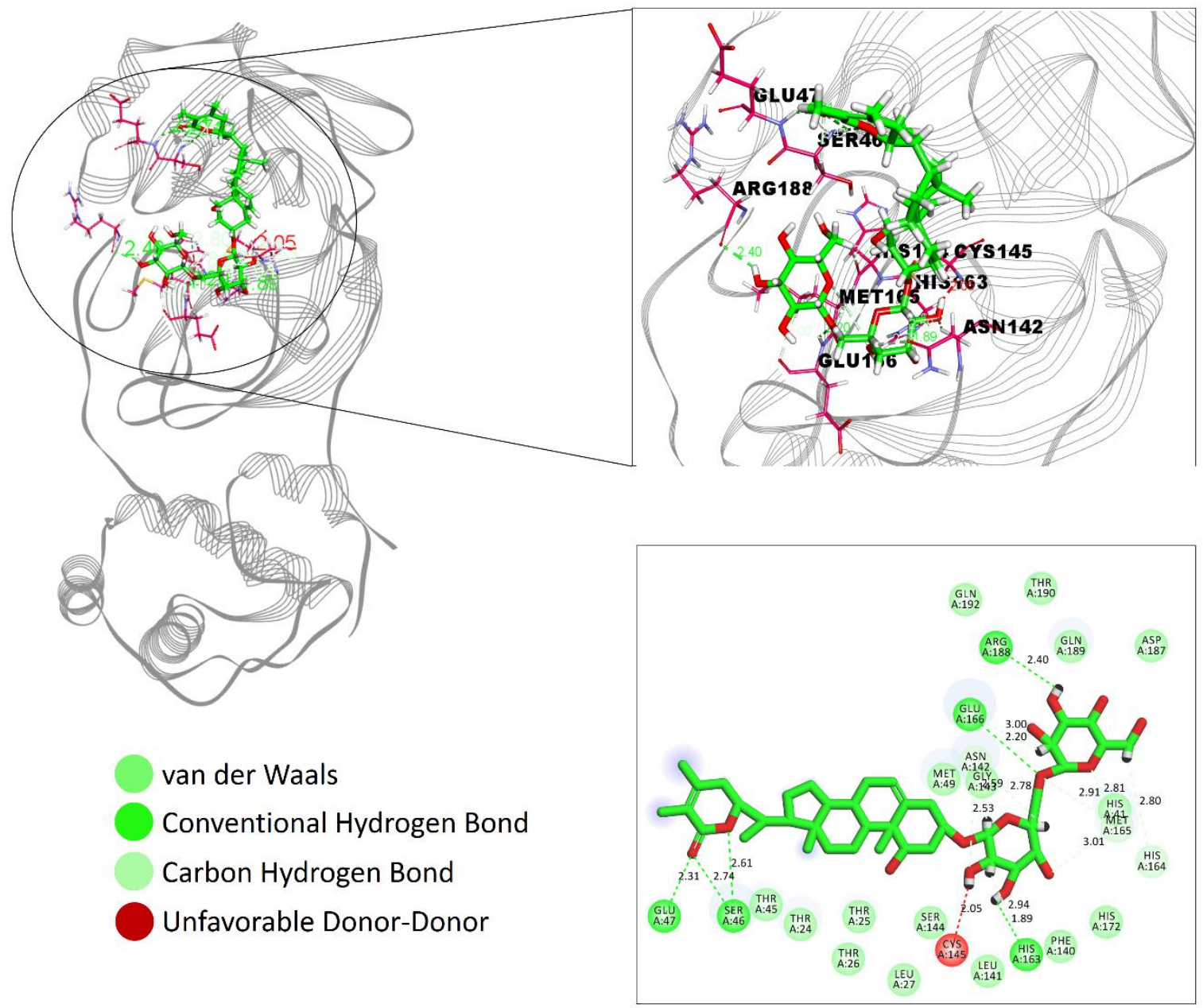

Fig-4 Interaction of Withanoside $\mathrm{V}$ in the binding cleft of SARS-CoV-2 M ${ }^{\text {ro }}$ (PDB ID: 6LU7) of COVID-19 shown in (a) $3 \mathrm{D}$ representation and (b) $2 \mathrm{D}$ representation (for better clarity) describing ligands interactions by formation of various $\mathrm{H}$-bonds and hydrophobic interactions with protein at the active site of the protein. 
A
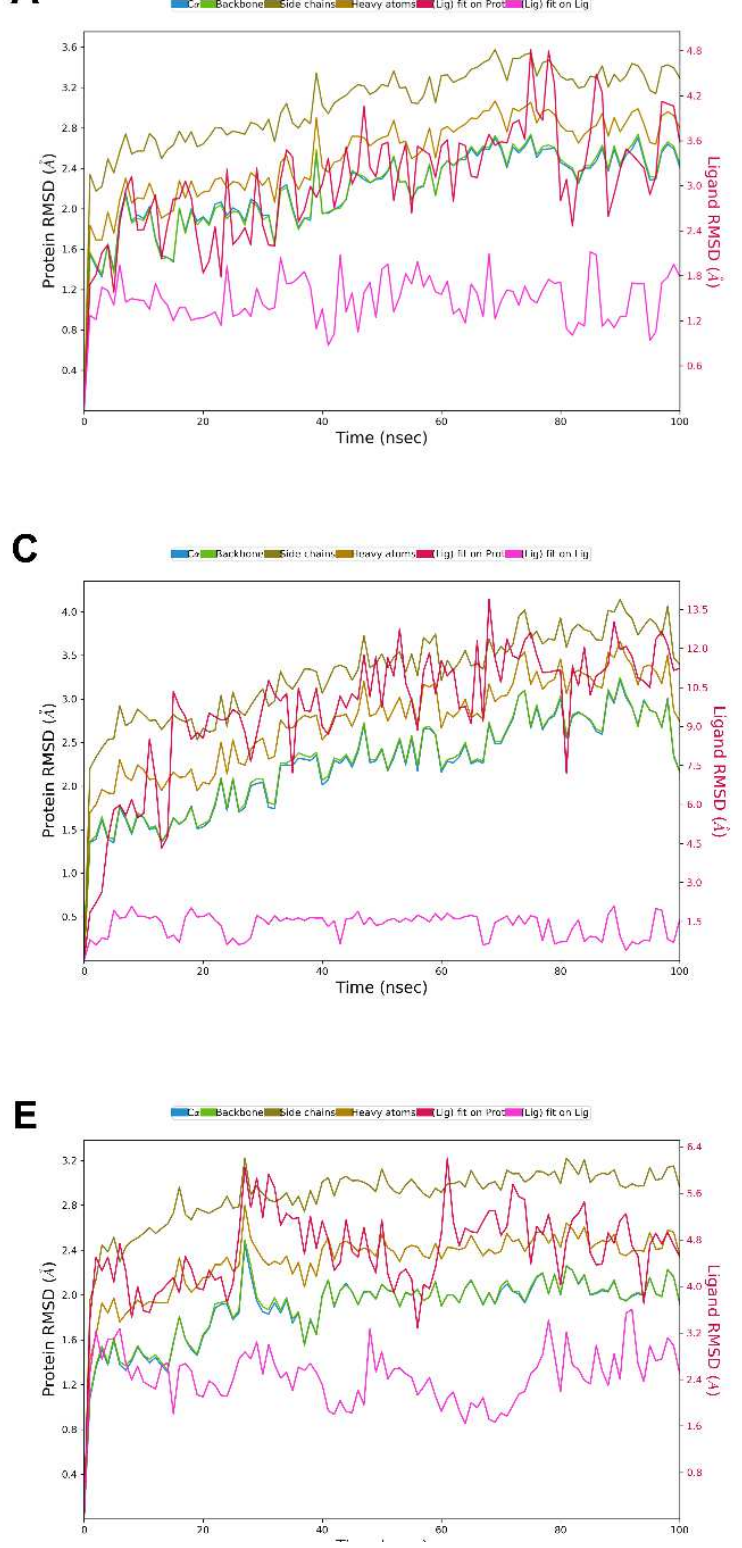

B

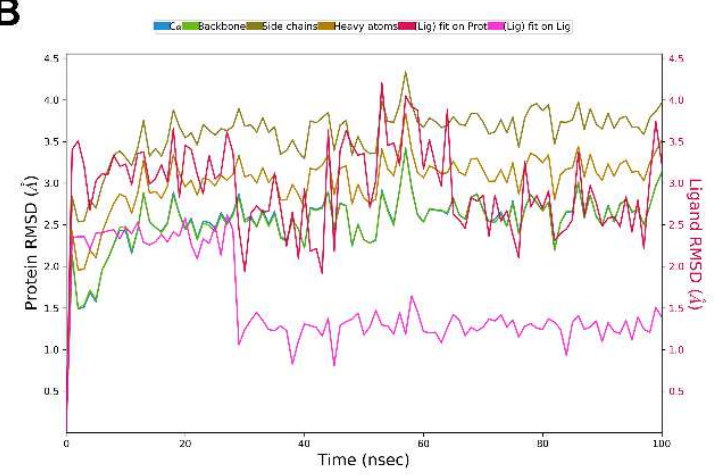

D

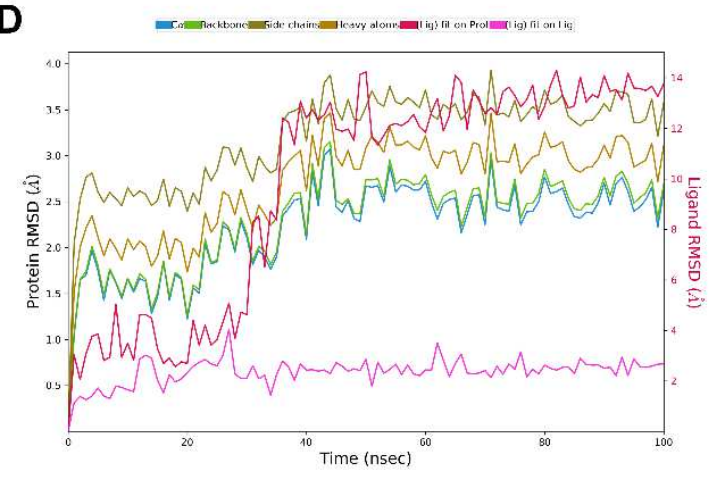

$\mathbf{F}$

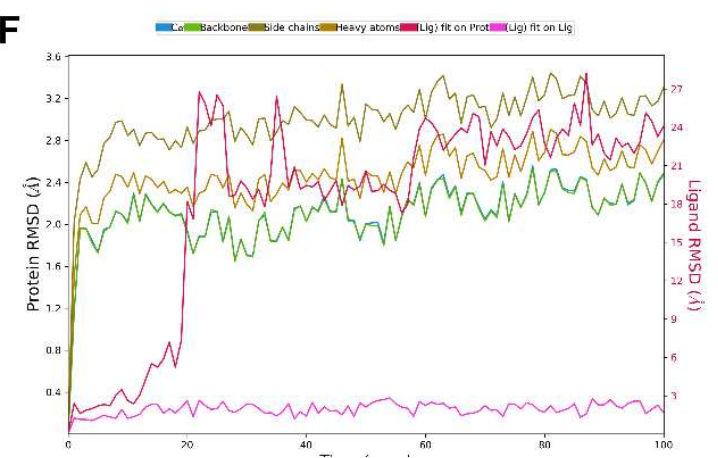

Fig-5 RMSD plot of HE target with co-crystal ligand and top-five phytochemicals as a function of simulation time. a. N3, b. Withanoside-V, c. Withanoside-VI, d. Racemoside-B, e. RacemosideA, f. Shatavarin-IX. 
A

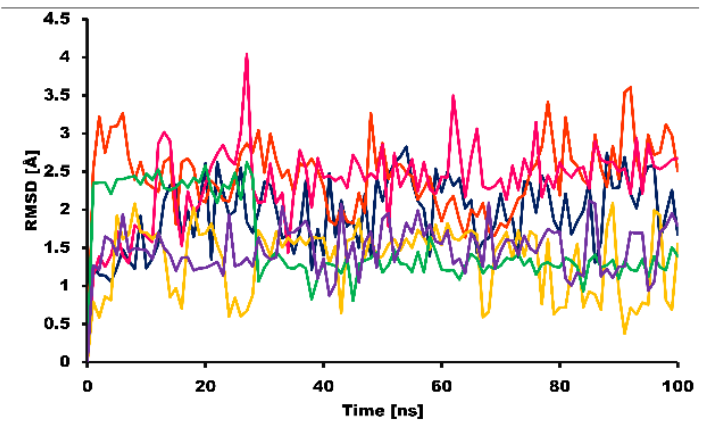

C

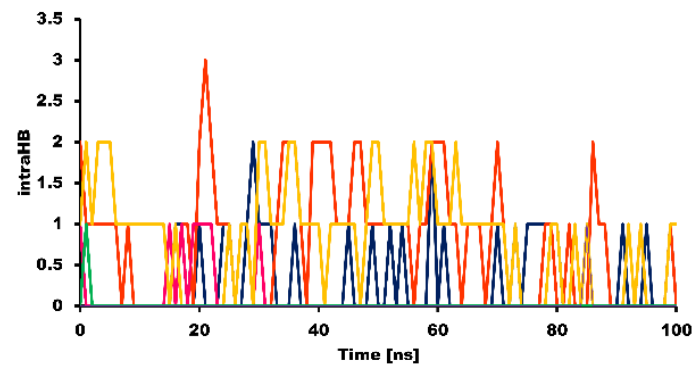

E

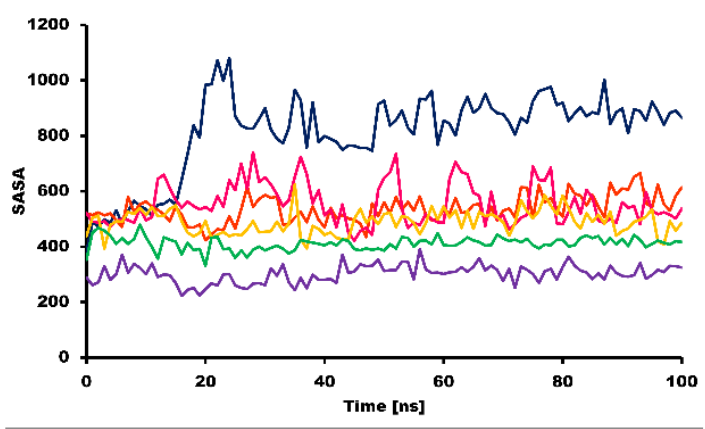

B

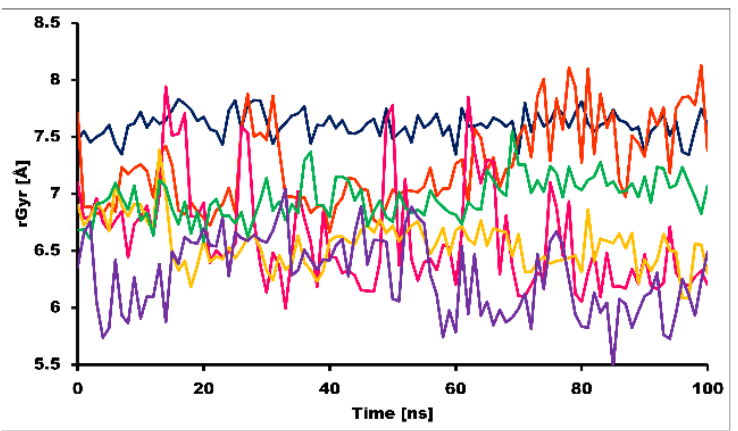

D

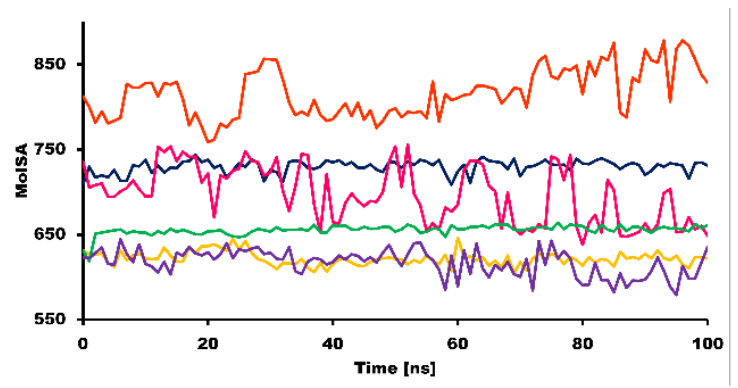

F

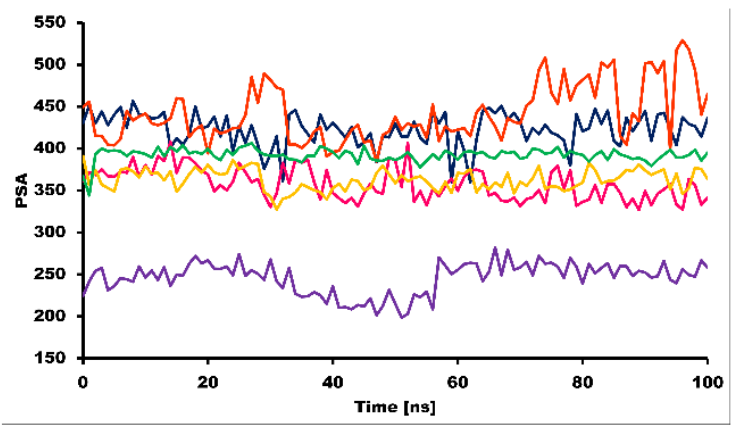

Fig-6 Various measures of the molecular dynamics simulations of co-crystal ligand and top-five phytochemicals with HE target. a. RMSD, b. rGyr, c. intra HB, d. MolSA, e. SASA and f. PSA. N3 (purple color), Withanoside-V (green color), Withanoside-VI (yellow color), Racemoside-B (magenta color), Racemoside-A (orange color), Shatavarin-IX (blue color). 

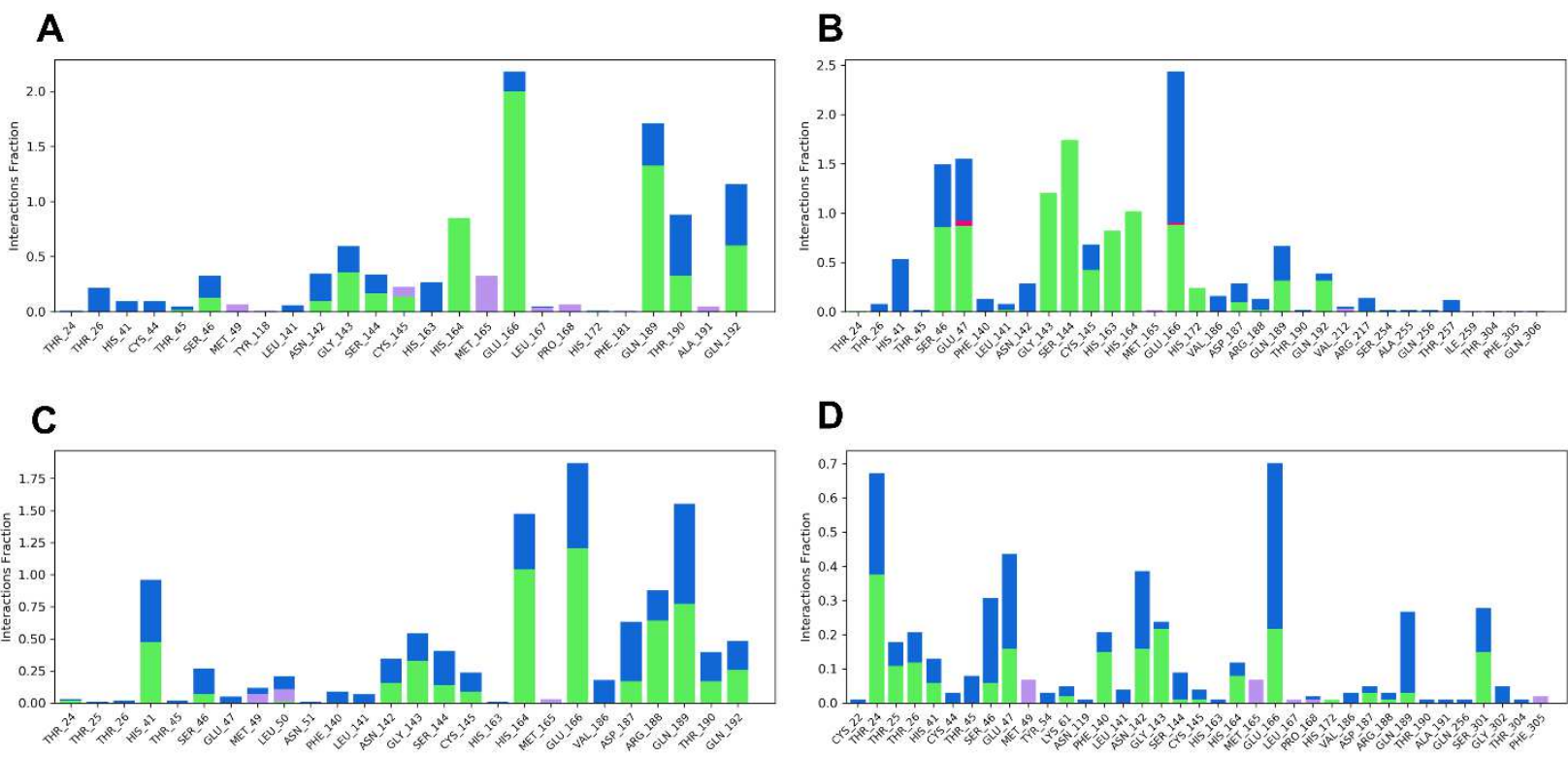

D
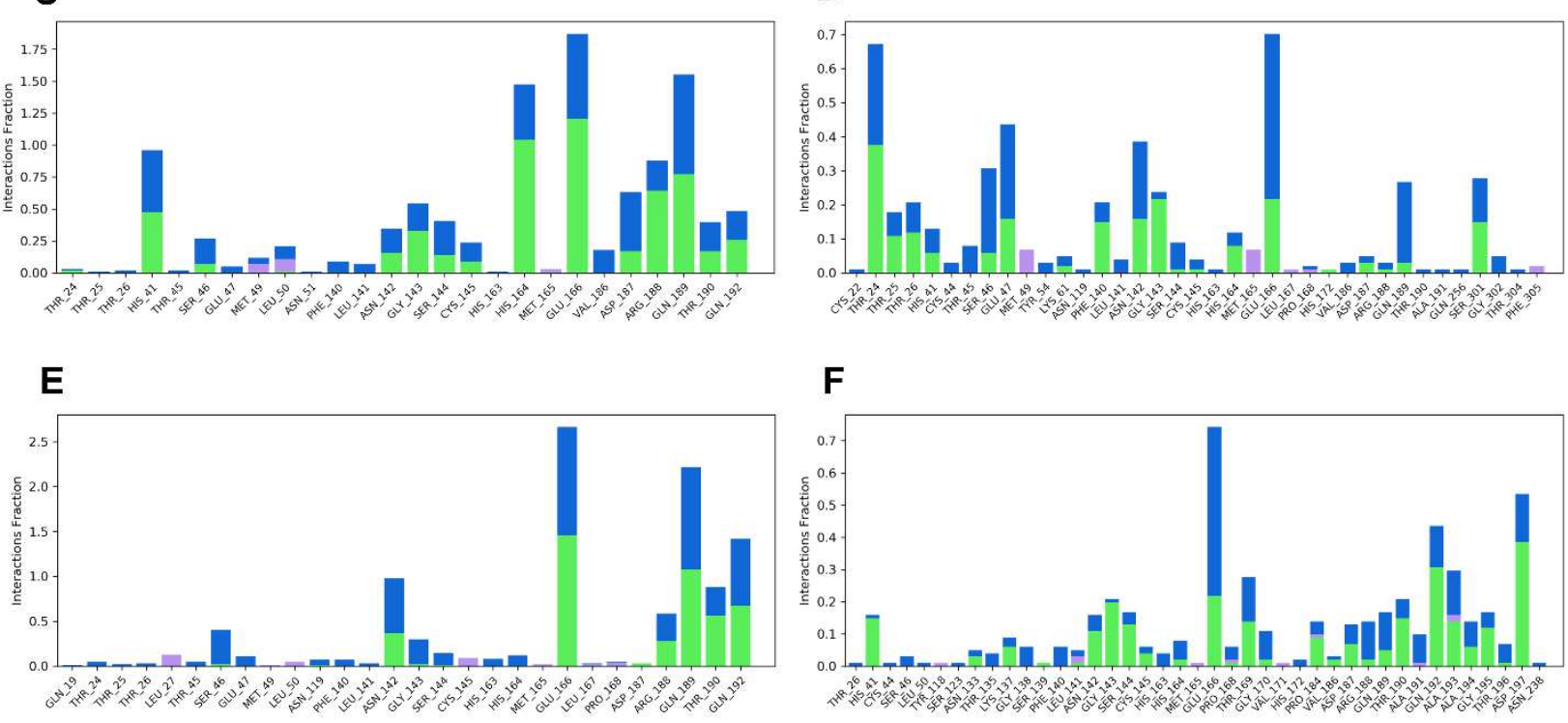

Fig-7 Various intermolecular interactions made by SARS-CoV-2 $\mathrm{M}^{\text {Pro }}$ pocket residues with cocrystal ligand and top-five phytochemicals compounds, captured during molecular dynamics simulations. a. N3, b. Withanoside-V, c. Withanoside-VI, d. Racemoside-B, e. Racemoside-A, f. Shatavarin-IX. 

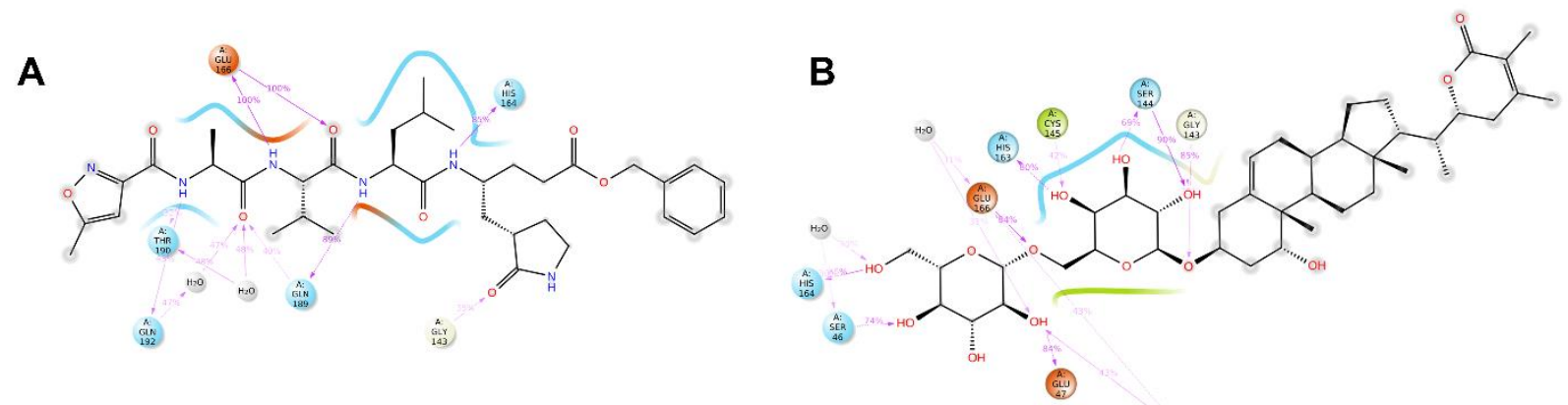

C

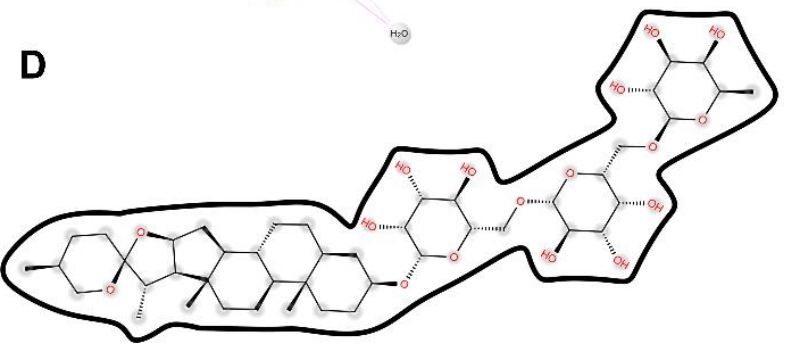

E

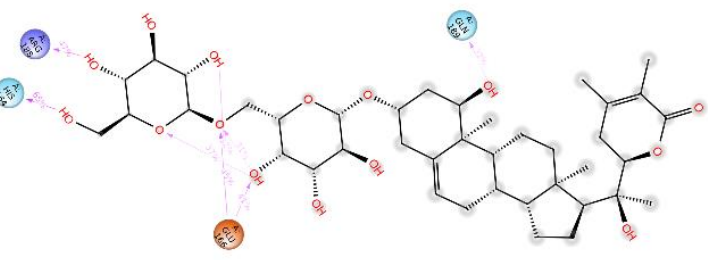
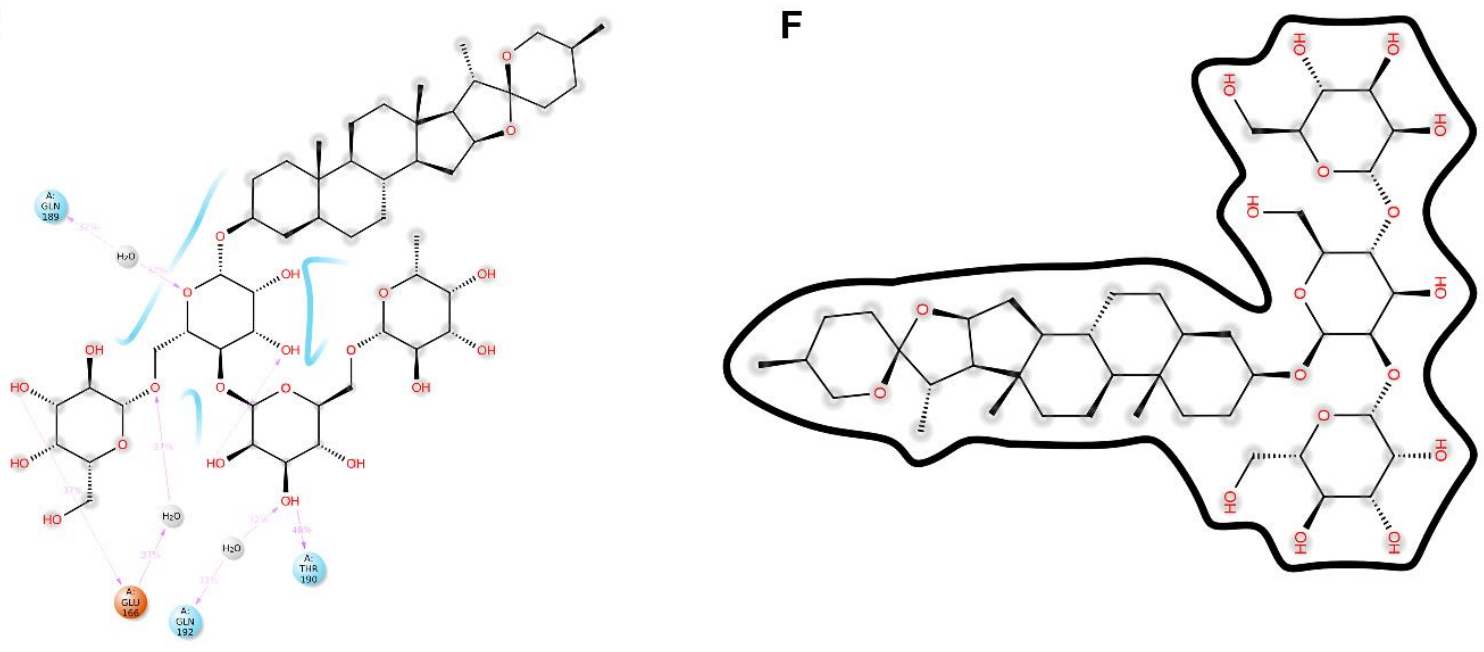

Fig-8 Preserved contacts of co-crystal ligand and top-five phytochemicals with SARS-CoV-2 $\mathrm{M}^{\mathrm{pro}}$ target, captured during molecular dynamics simulations. 


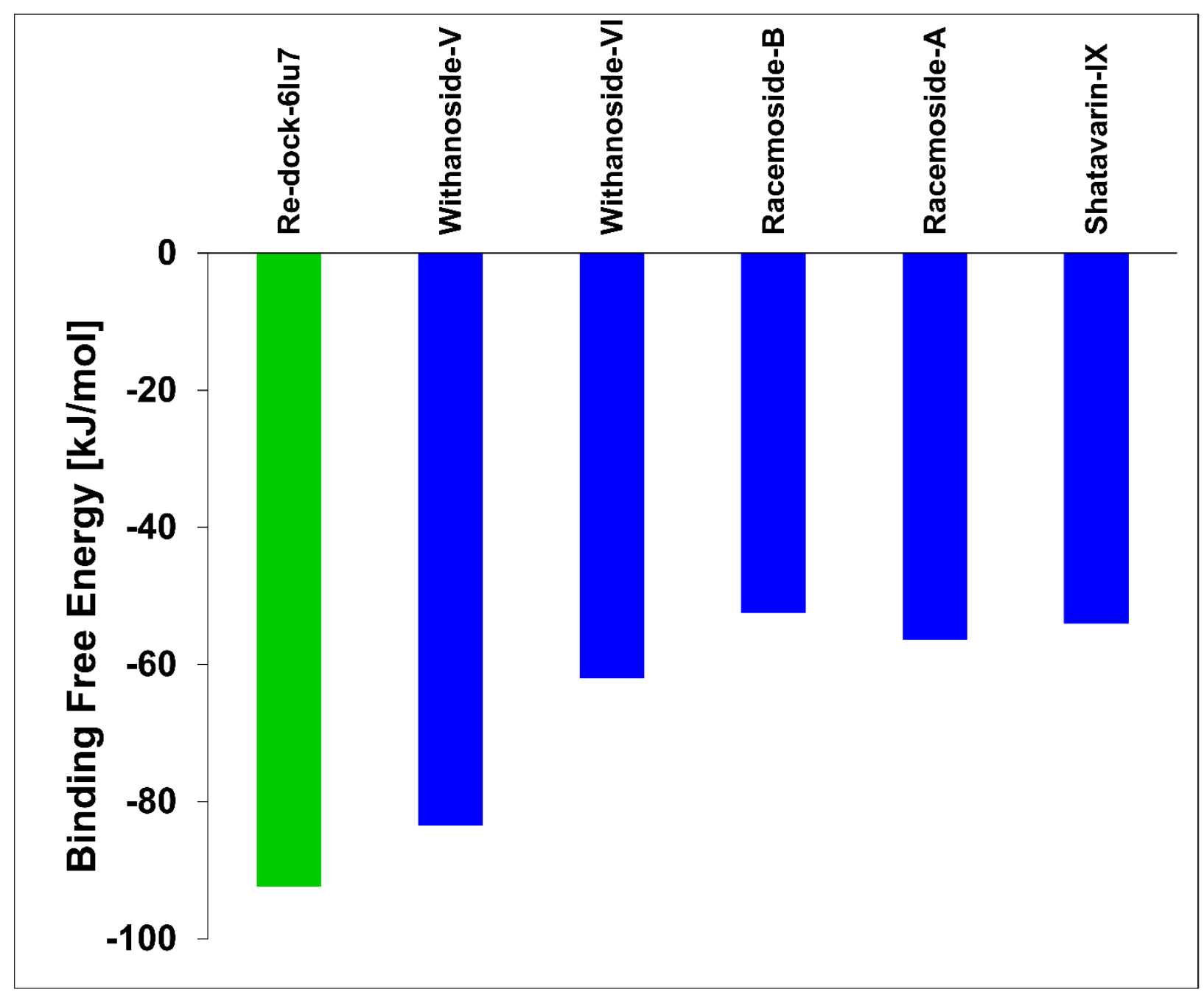

Fig-9 Binding free energy calculations of co-crystal ligand and top-five phytochemicals compounds with SARS-CoV-2 $\mathrm{M}^{\text {Pro }}$ target. The co-crystal ligand of SARS-CoV-2 $\mathrm{M}^{\text {Pro }}$ target, N3, is shown in green color bar. The phytochemicals are represented in blue color bars. 


\section{List of Tables}

Table-1 QikProp calculation of Physico-chemical properties and ADME/T properties

\begin{tabular}{|c|c|c|c|c|c|c|}
\hline Compounds & $\begin{array}{c}\text { Rule of } \\
\text { five }\end{array}$ & PSA & QPlogPo/w & QPpolrz & QPlogBB & QPlogKp \\
\hline $\begin{array}{c}\text { Withanoside- } \\
\text { V }\end{array}$ & $\begin{array}{c}\text { No } \\
\text { violation }\end{array}$ & 301.363 & -2.036 & 86.641 & -4.397 & -5.831 \\
\hline $\begin{array}{c}\text { Withanoside- } \\
\text { VI }\end{array}$ & $\begin{array}{c}\text { No } \\
\text { violation }\end{array}$ & 246.197 & 0.004 & 80.703 & -4.735 & -6.273 \\
\hline $\begin{array}{c}\text { Racemoside- } \\
\text { B }\end{array}$ & $\begin{array}{c}\text { No } \\
\text { violation }\end{array}$ & 259.608 & -0.992 & 77.748 & -4.722 & -6.38 \\
\hline $\begin{array}{c}\text { Racemoside- } \\
\text { A }\end{array}$ & $\begin{array}{c}\text { No } \\
\text { violation }\end{array}$ & 241.348 & -1.014 & 67.872 & -4.843 & -6.817 \\
\hline $\begin{array}{c}\text { Shatavarin- } \\
\text { IX }\end{array}$ & $\begin{array}{c}\text { No } \\
\text { violation }\end{array}$ & 224.561 & -0.526 & 67.865 & -4.757 & -6.397 \\
\hline
\end{tabular}




\section{Figures}

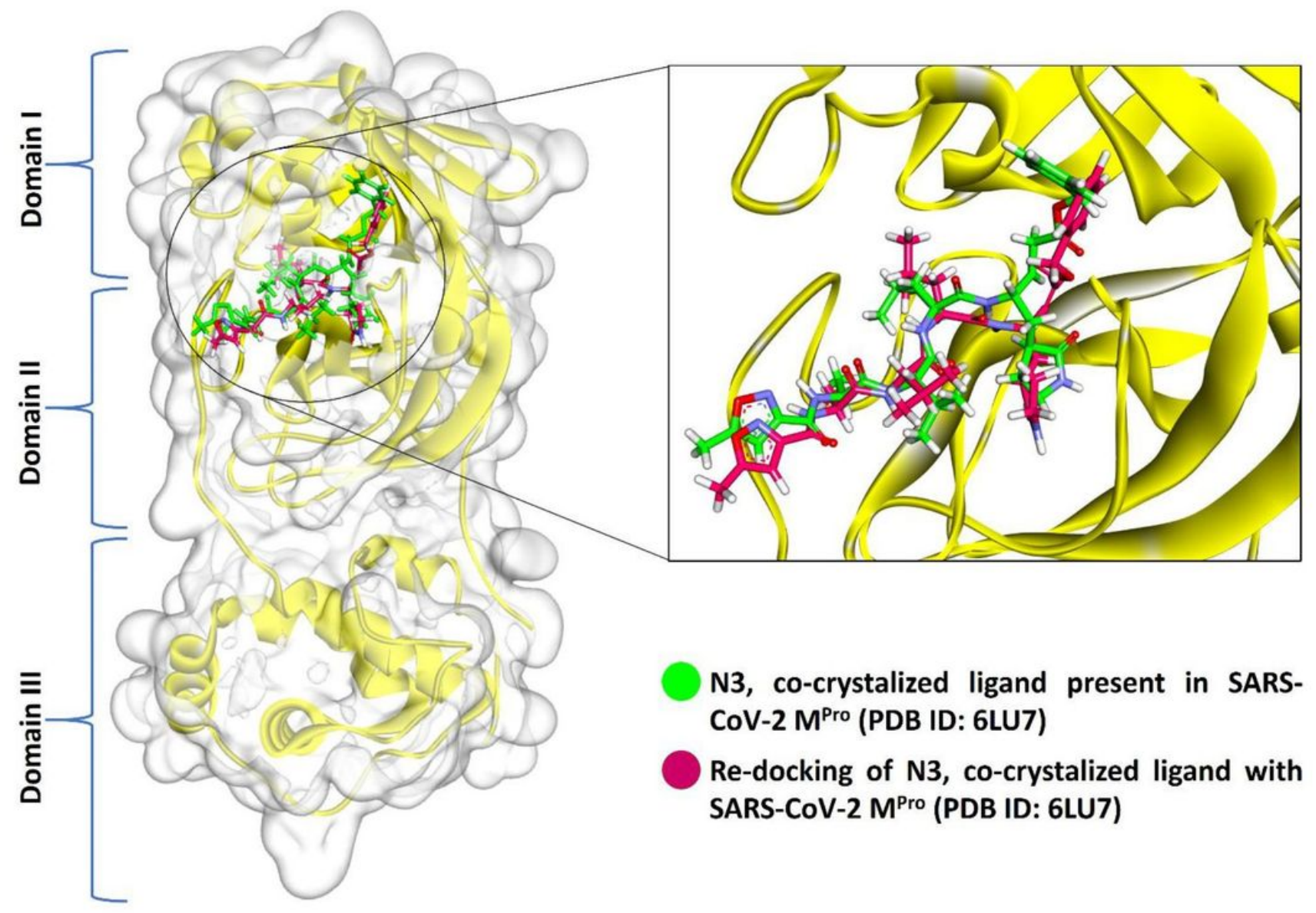

Figure 1

Three-dimensional representation of the co-crystal ligand N3 in the binding cleft of SARSCoV-2 MPro (PDB ID: 6LU7). Green color represents the pre-docked pose of co-crystal ligand N3 and re-docked pose of co-crystal ligand N3 was preserved in magenta color. 


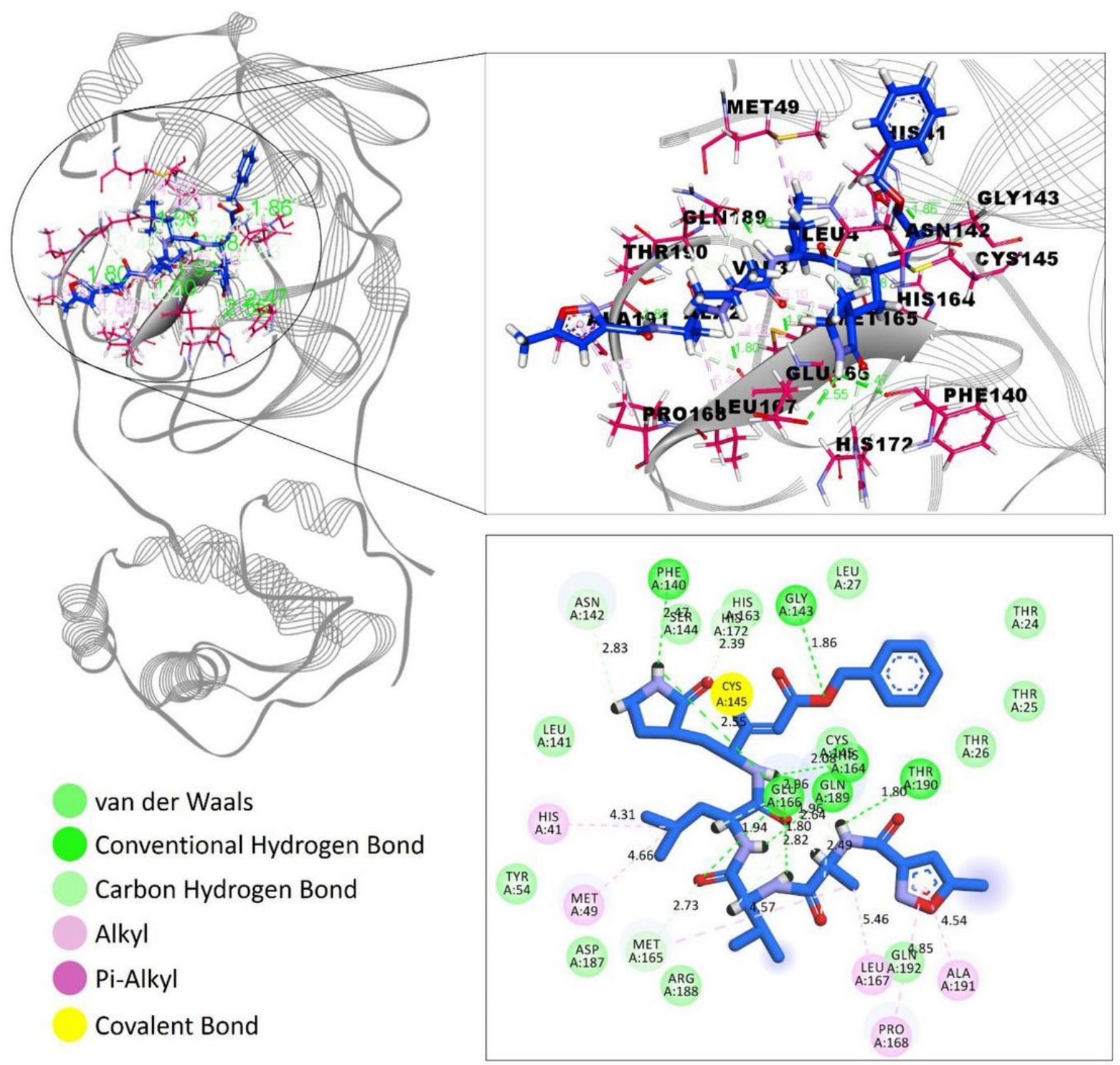

Figure 2

Interaction of N3 in the binding cleft of SARS-CoV-2 MPro (PDB ID: 6LU7) of COVID-19 shown in (a) 3 D representation and (b) $2 \mathrm{D}$ representation (for better clarity) describing ligands interactions by formation of various $\mathrm{H}$-bonds and hydrophobic interactions with protein at the active site of the protein. 


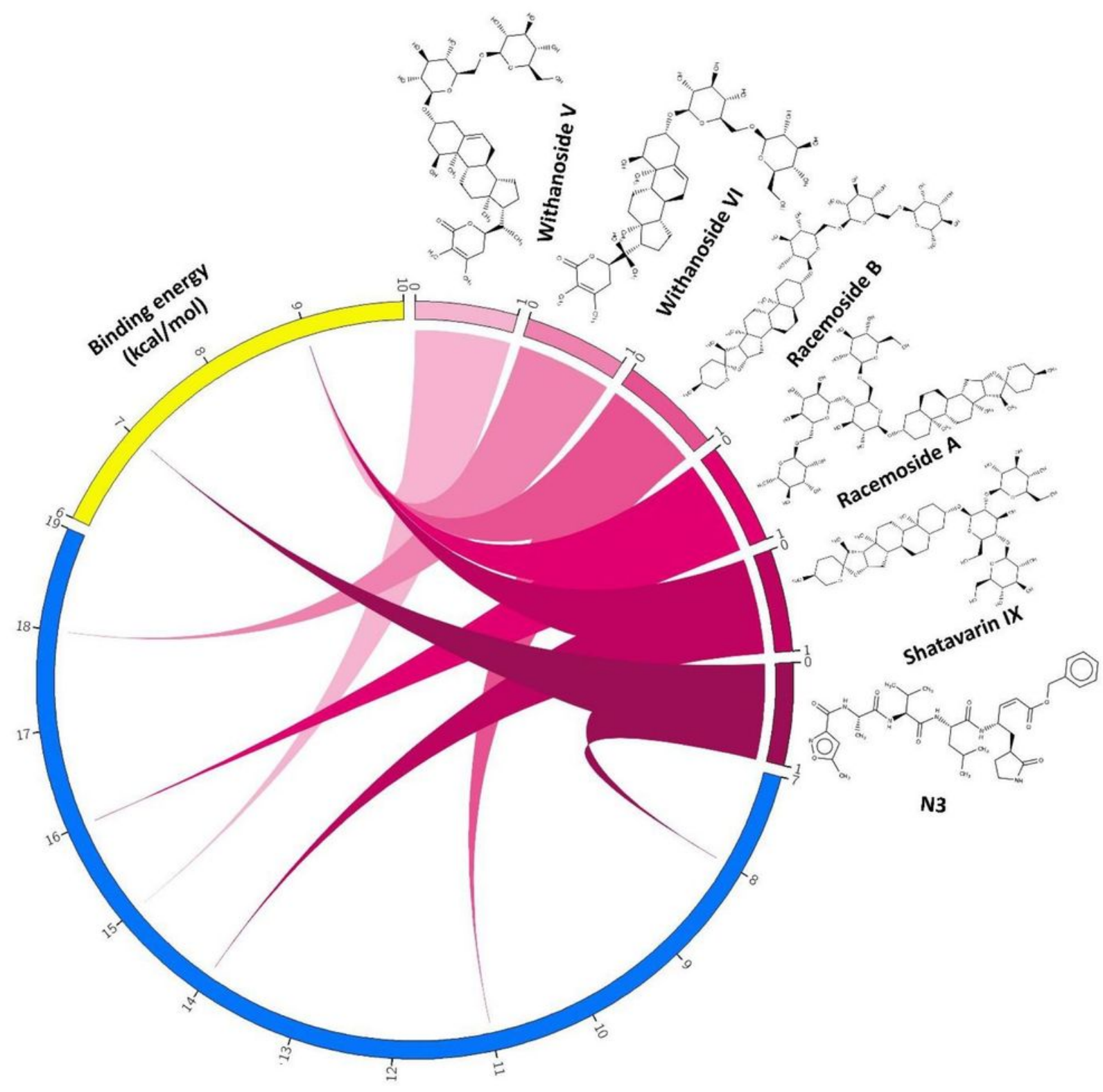

Hydrogen bonds

\section{Figure 3}

N3, Withanoside-V, Withanoside-VI, Racemoside-B, Racemoside-A, Shatavarin-IX are depicted along with their Hydrogen bonds and Binding energy information using Circos representation. All the 3 entities- the compounds, Hydrogen bond and Binding energy are shown using 3 separate ideograms. The 6 compounds are drawn from light to dark magenta color shades and their respective values of Hydrogen bond (Blue color) and Binding energy (Yellow color) are displayed using connecting colored ribbons and numbering scales. 


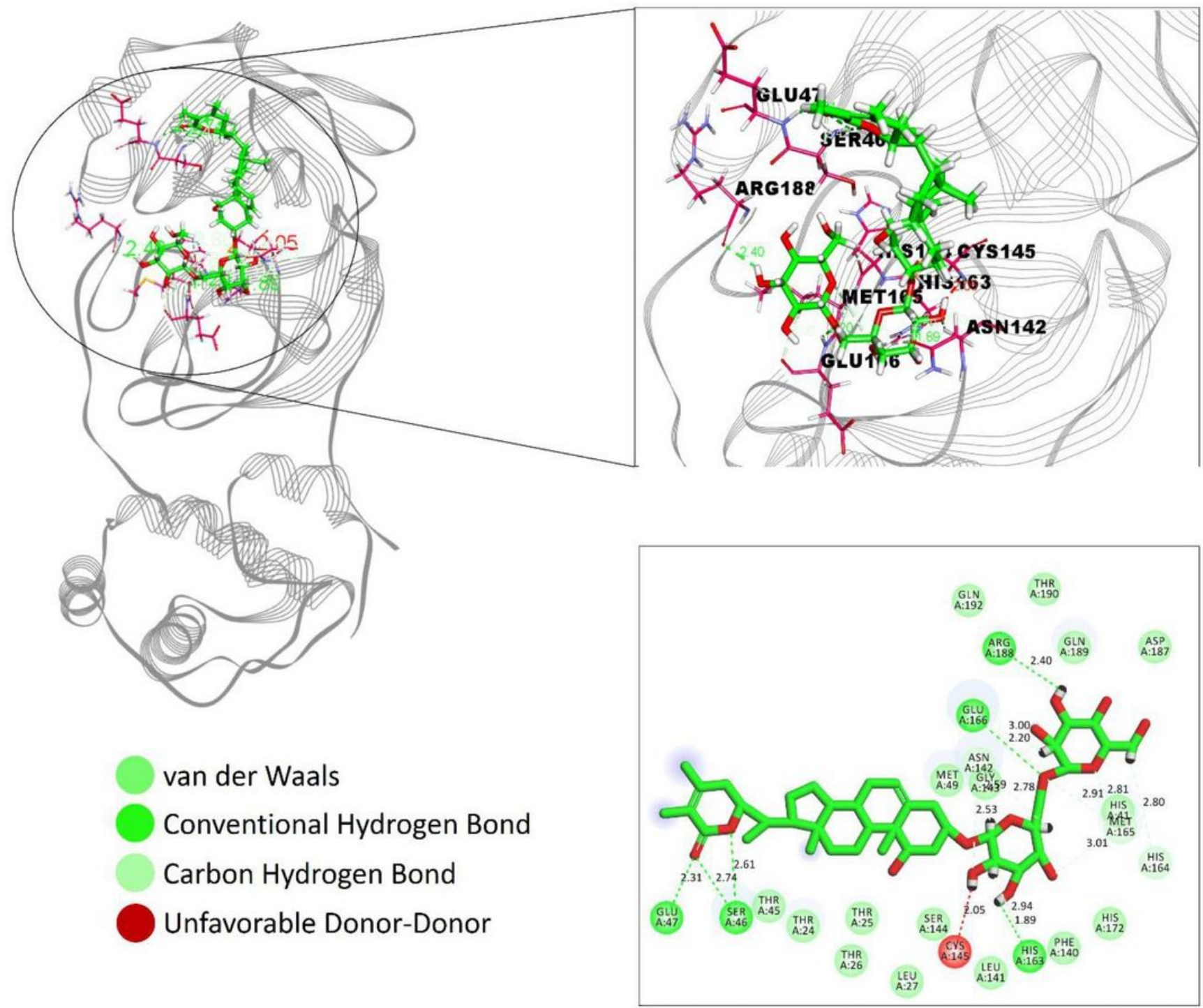

Figure 4

Interaction of Withanoside $\mathrm{V}$ in the binding cleft of SARS-CoV-2 MPro (PDB ID: 6LU7) of COVID-19 shown in (a) $3 \mathrm{D}$ representation and (b) $2 \mathrm{D}$ representation (for better clarity) describing ligands interactions by formation of various $\mathrm{H}$-bonds and hydrophobic interactions with protein at the active site of the protein. 
A
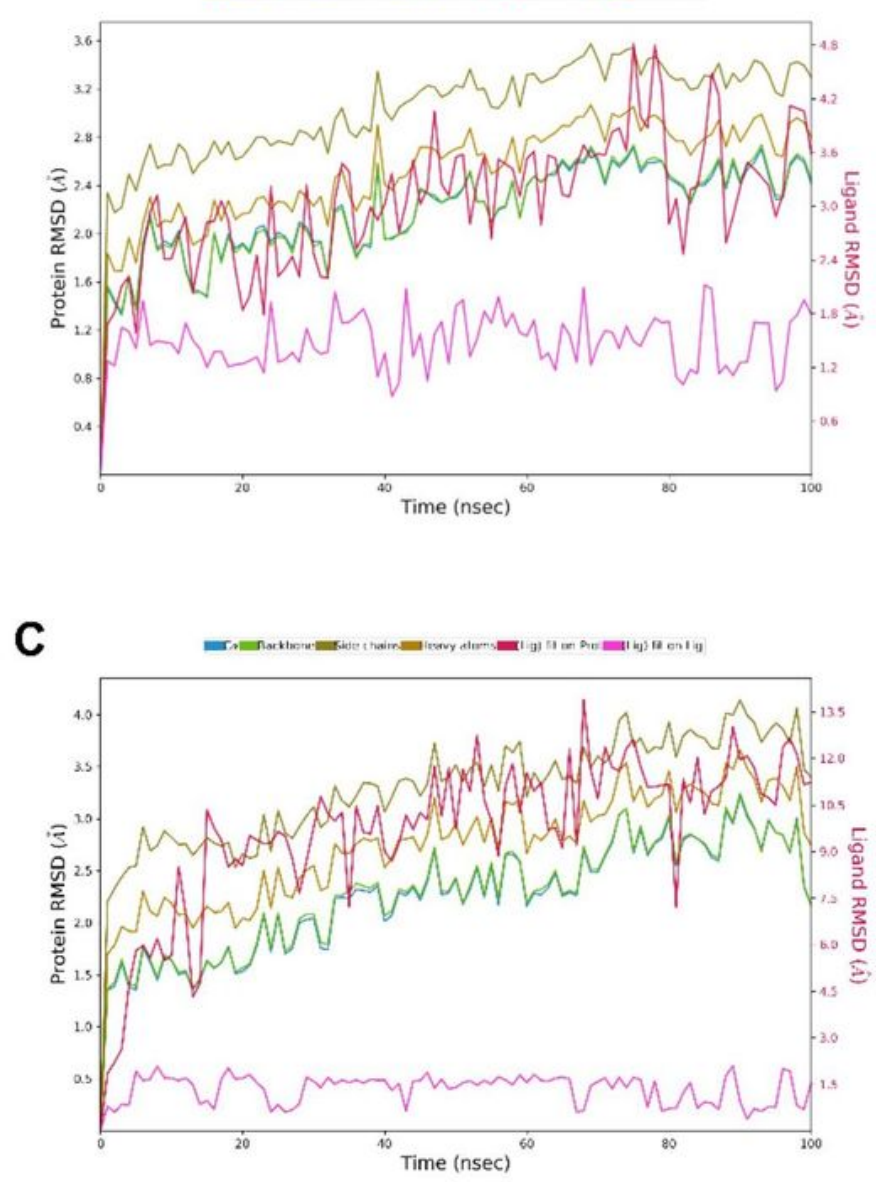

E

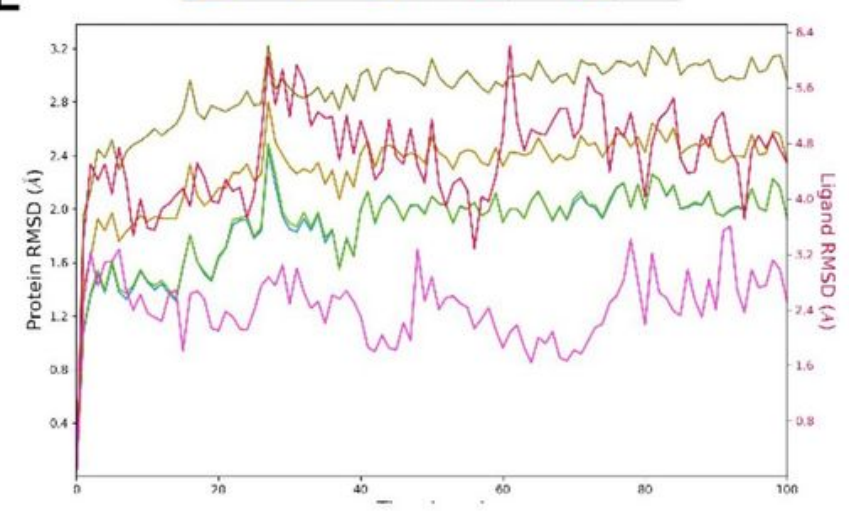

B

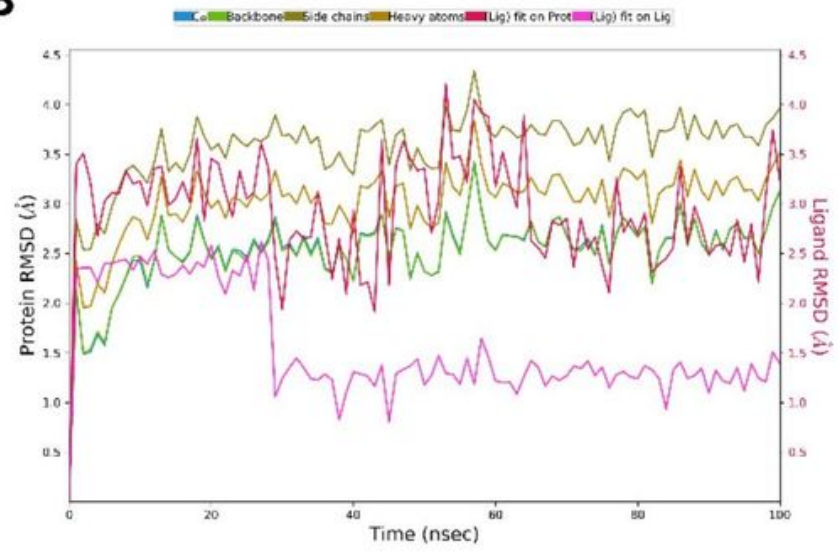

D

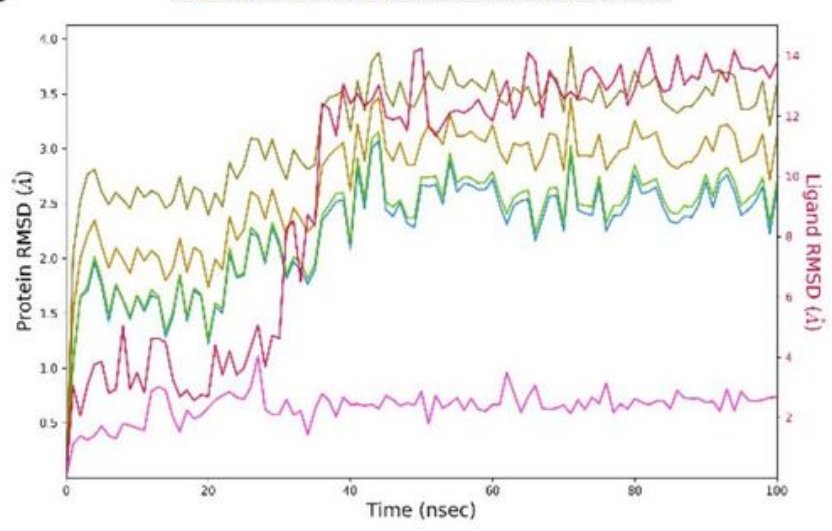

$\mathbf{F}$

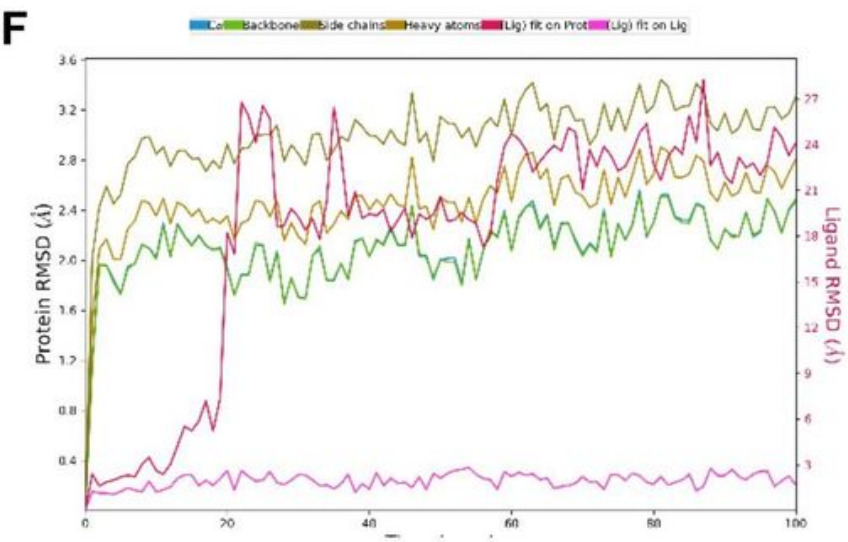

\section{Figure 5}

RMSD plot of HE target with co-crystal ligand and top-five phytochemicals as a function of simulation time. a. N3, b. Withanoside-V, c. Withanoside-VI, d. Racemoside-B, e. RacemosideA, f. Shatavarin-IX. 
A

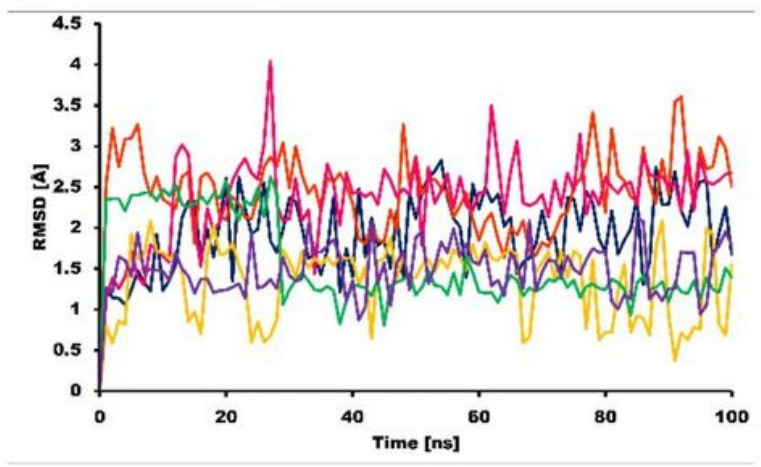

C

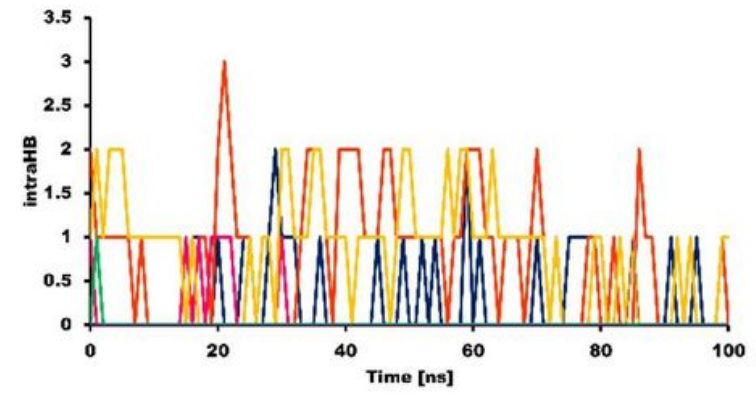

E

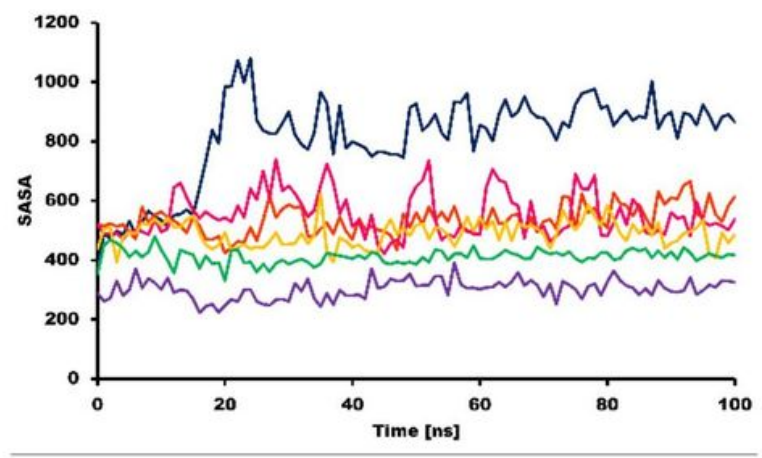

B

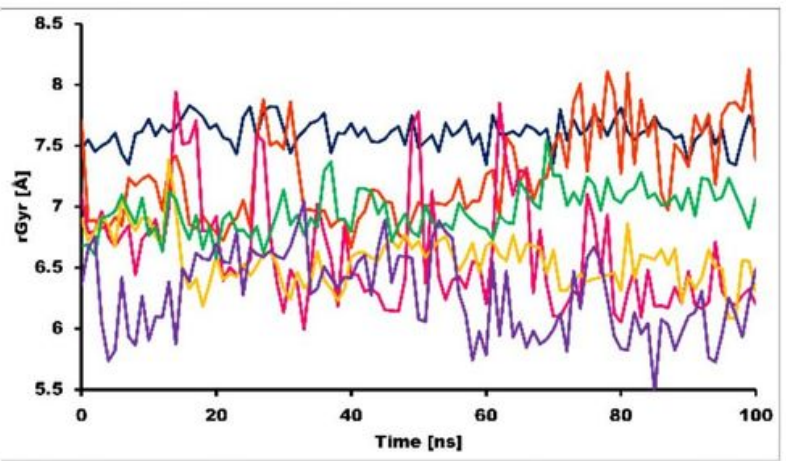

D

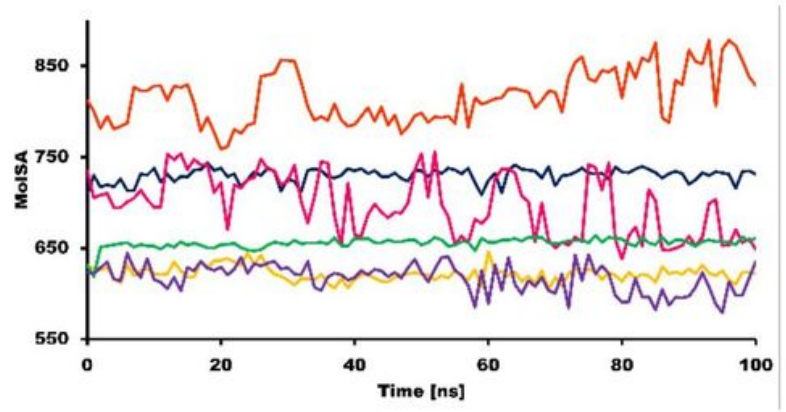

$\mathbf{F}$

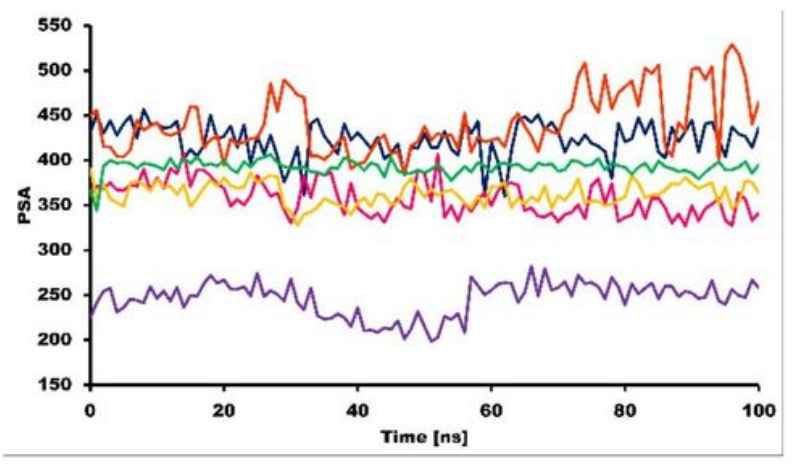

Figure 6

Various measures of the molecular dynamics simulations of co-crystal ligand and top-five phytochemicals with HE target. a. RMSD, b. rGyr, c. intra HB, d. MoISA, e. SASA and f. PSA. N3 (purple color), Withanoside-V (green color), Withanoside-VI (yellow color), Racemoside-B (magenta color), Racemoside-A (orange color), Shatavarin-IX (blue color). 
A

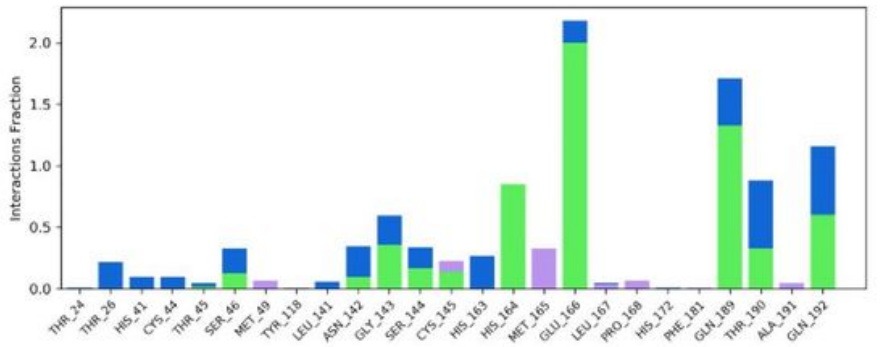

C

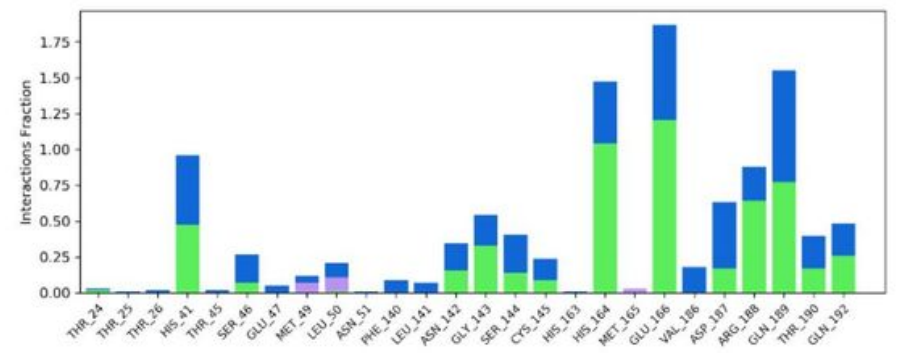

E

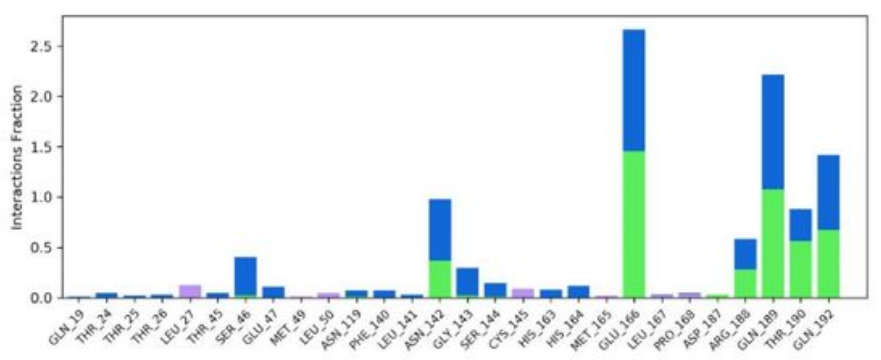

B

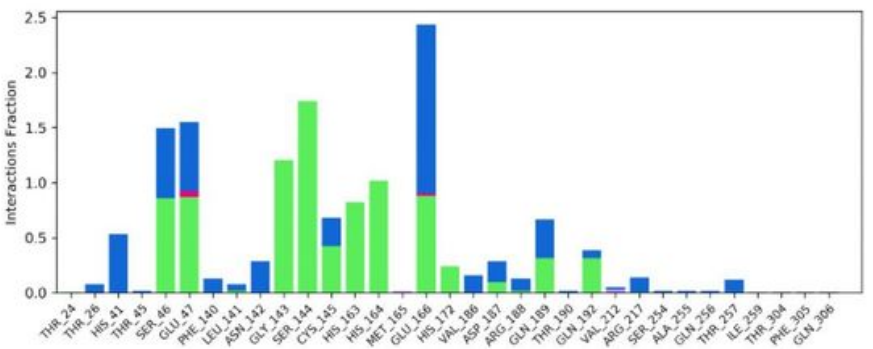

D

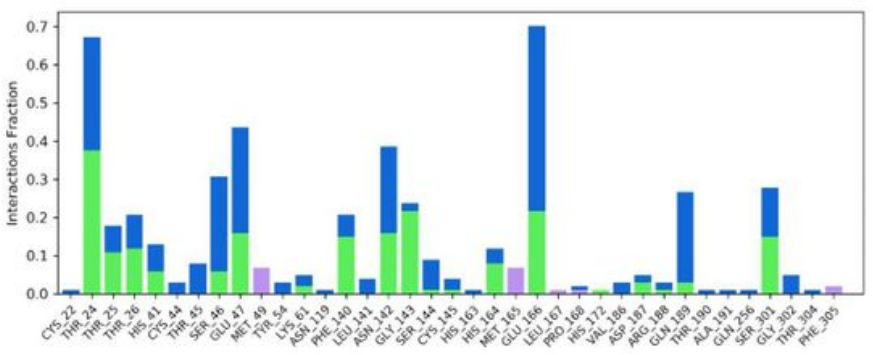

$\mathbf{F}$

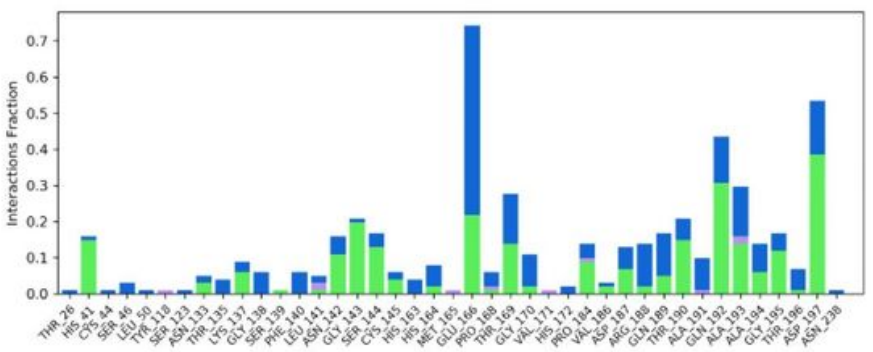

Figure 7

Various intermolecular interactions made by SARS-CoV-2 MPro pocket residues with cocrystal ligand and top-five phytochemicals compounds, captured during molecular dynamics simulations. a. N3, b. Withanoside-V, c. Withanoside-VI, d. Racemoside-B, e. Racemoside-A, f. Shatavarin-IX. 
A

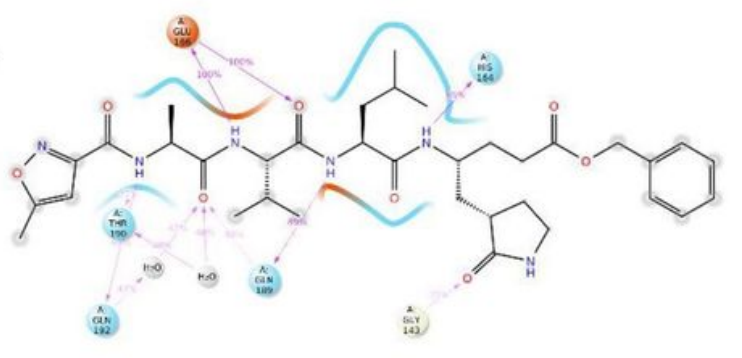

C

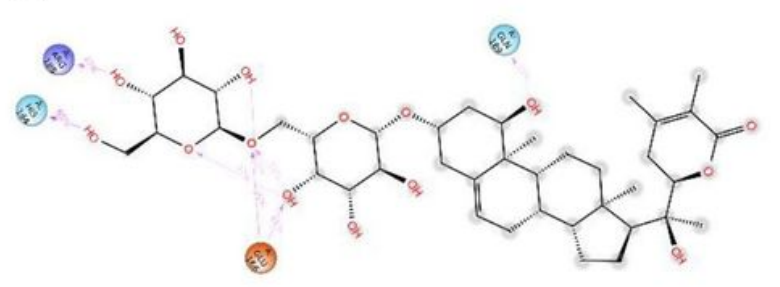

E

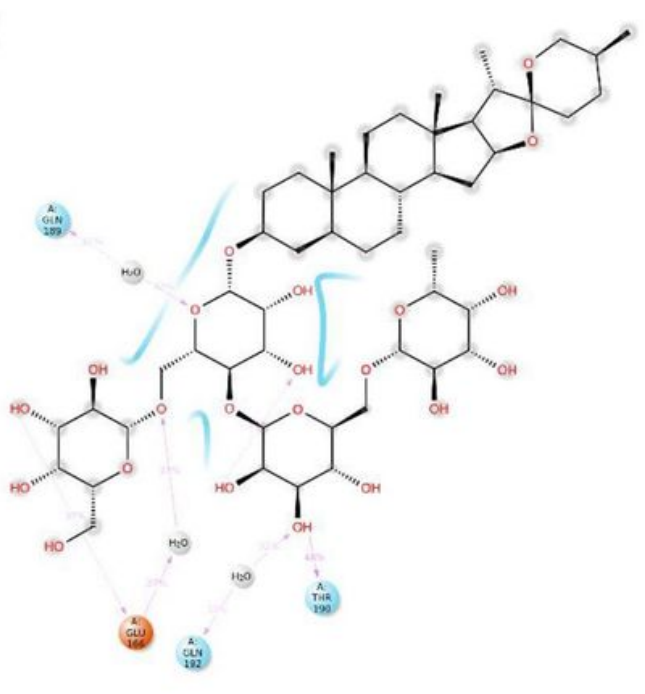

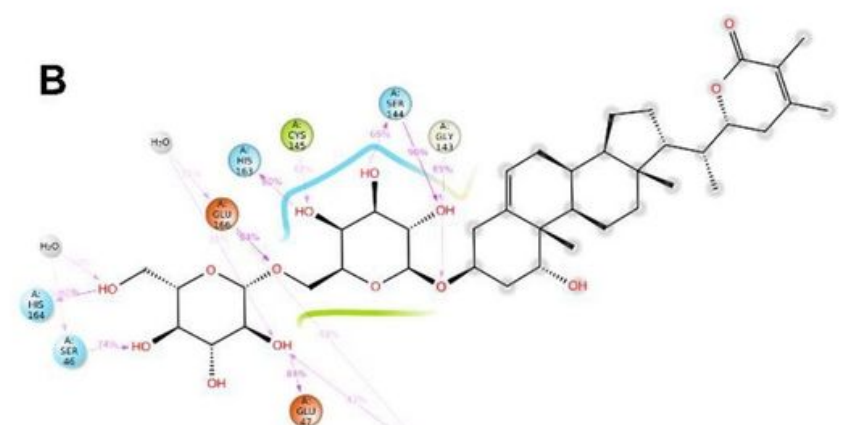

D

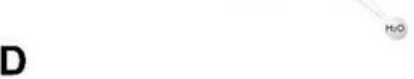

$+\infty$
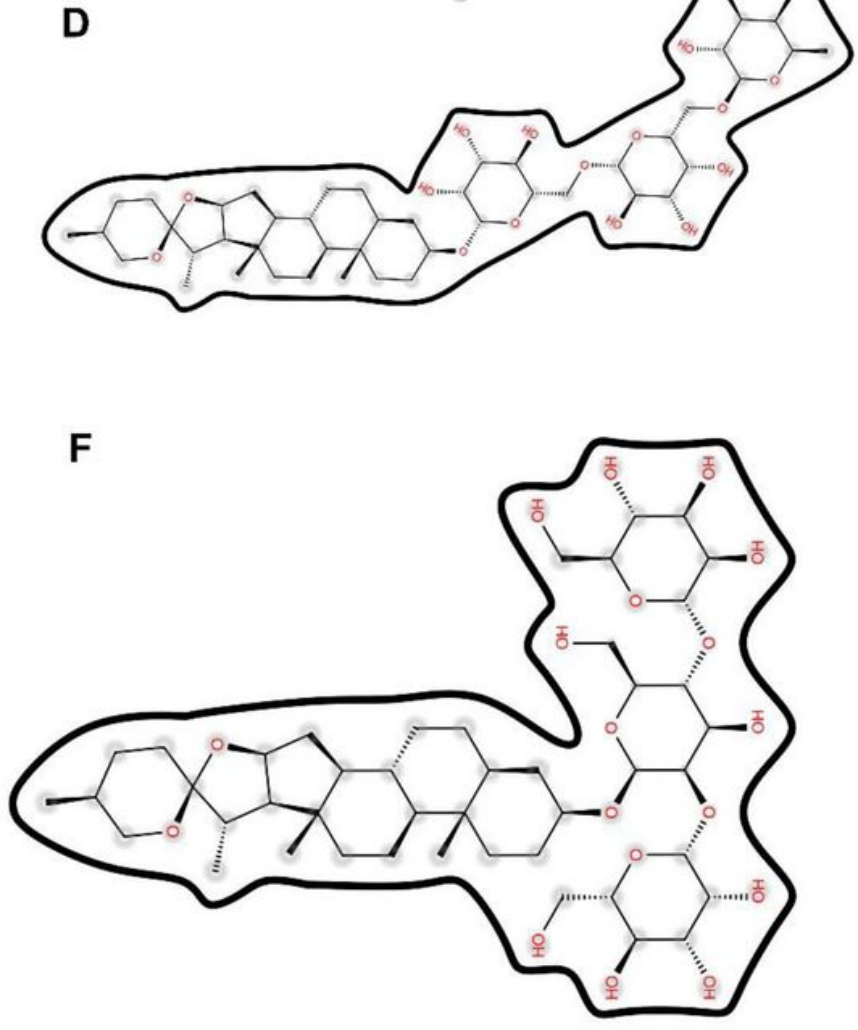

Figure 8

Preserved contacts of co-crystal ligand and top-five phytochemicals with SARS-CoV-2 MPro target, captured during molecular dynamics simulations. 


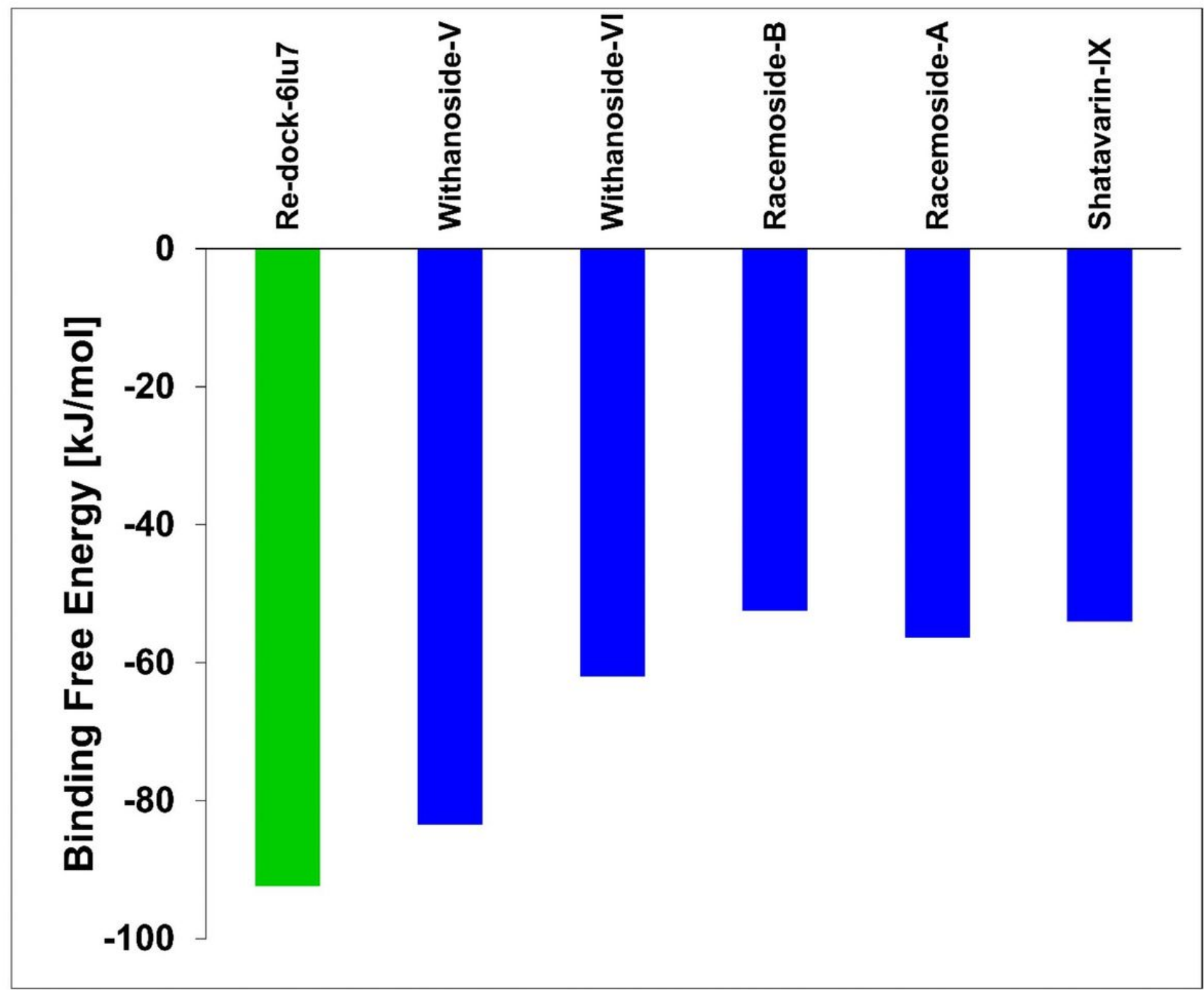

Figure 9

Binding free energy calculations of co-crystal ligand and top-five phytochemicals compounds with SARSCoV-2 MPro target. The co-crystal ligand of SARS-CoV-2 MPro target, N3, is shown in green color bar. The phytochemicals are represented in blue color bars.

\section{Supplementary Files}

This is a list of supplementary files associated with this preprint. Click to download.

- SUPPLEMENTARYFILE.pdf 